
MCMASTER UNIVERSITY LIBRARY RC 415.V5 1911

Treatment of neurasthenia by $t$ 



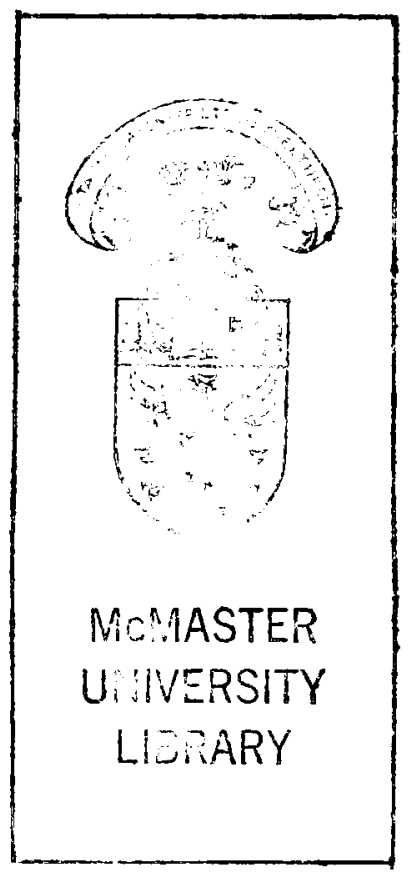





\title{
TREATMENT OF
}

\section{NEURASTHENIA}

BY TEACHING OF BRAIN CONTROL

\author{
BY \\ DR. ROGER VITTOZ
}

TRANSLATED BY

H. B. BROOKE

LONGMANS, GREEN, AND CO.

39 PATERNOSTER ROW, LONDON NEW YORK, BOMBAY, AND CALCUTTA

$$
\text { I9I I }
$$



Treatment of Neurasthenia by the Teaching of Brain Control. 



\section{TABLE OF CONTENTS}

INTRODUCTION

PAGE

Brain Control : I

Duality of the brain - $\quad$ I

Definition of brain control 3

Effect of insufficient brain control on the ideas, feelings, and actions - - 6

Effect of insufficient brain control on the bodily organs

Brain control in cases of neurasthenia 9

NEURASTHENIA -

Psychic SyMptoms : - - - $\quad$ I6

Symptoms of the chronic state $\quad$ - 19

Distress of mind $\quad$ - 23

Lack of will $\quad 23$

Physiological (organic) symptoms due to insuffcient brain control $\quad-\quad 24$

The Necessity of Training the Brain Control: 27 How to control the brain - $\quad 29$

Abnormal conditions of the brain - 33

Normal and abnormal vibrations - 34

How to modify abnormal vibrations - $\quad 36$ 
Treatment :-

Functional treatment

Control of the actions 40

Voluntary actions - 45

Psychic effect of control over the actions $\quad 46$

Control of the IDEAS :

The idea should be conscious - 49

State of consciousness $\quad 5^{\circ}$

Conditions of the brain $\quad 52$

COnCEntration: - - $\quad 56$

Concentration on an idea - $\quad 63$

Physiological effects of concentration $\quad 66$

Elimination and De-Concentration 70

THE WILL : - - - - $\quad 74$

Effort of the will - $\quad 76$

Errors - $\quad 84$

The rôle of effort of will in the case of insufficient control - $\quad 87$

Psychical Treatment : $\quad$ - $\quad 89$

Reappearance of former bad symptoms owing to impressions left on the brain $\quad 9$ I

The abnormal working and idess of the brain 94

Diminution of the reactive faculties - 9!

Cause of relapses $\quad-\quad \quad \quad \quad$ 10:

INSOMNIA 


\section{INTRODUCTION.}

So many works on this subject have appeared of recent years that I hope I may be excused if $I$ add this modest contribution to the number; one of my chief reasons for doing so is a desire to comply with wishes expressed by my patients. I should also like to describe the treatment from my own point of view, and to throw light on the causes of those nervous illnesses known as neurasthenia, psychoneurosis or psychasthenia.

As I am addressing myself chiefly to those suffering from these illnesses, I will endeavour to simplify as far as possible whatever part of this treatise might seem to them obscure. My object is to show them as well as I can why they are ill and how they can cure themselves.

My method of training is founded on the fact that every form of neurasthenia is due to the brain working abnormally; only by realizing this is it possible to arrive at a cure. 
I will now try to explain this abnormal working of the brain, its causes, and the treatment by which it may be overcome.

The title of this treatise explains itself; it is only by studying the brain control of those suffering from neurasthenia that imperfections of that control can be realized; the psychological causes of such illnesses are due to insufficient brain control, and by realizing this insufficiency we shall arrive at the necessary mode of treatment.

I admit that fuller explanations should no doubt be given of certain facts, but the reader must bear in mind that it is my wish to give here as concise an outline of the treatment as possible.

I would ask that the results I have obtained may be accepted in proof of my theory, and would beg my colleagues not to pass too hasty a judgement on the treatment I am about to: describe.

My object will have been attained if this simple treatise should be the means of affording to those who are ill (namely, to those suffering from what I will call insufficient brain conitrol) any help, or if it should even afford them some hope of a cure. 


\section{BRAIN CONTROL.}

DUALITY OF THE BRAIN.

BEFORE dealing with the question of brain control it is of the highest importance to realize the working of the brain in regard to its faculties of perception and elaboration of ideas, sensations and actions.

Of the many modern theories let us take the most simple, i.e. that which admits of two different working centres, called the conscious or objective, and the unconscious or subjective brain.

While admitting that none of the above expressions give a precise definition, we will employ the terms objective and subjective. The existence of two brains having been accepted as a fact, we will admit that the subjective brain is in a general way the source of the ideas and sensations, and that the objective brain in a sense "focusses" them, that is to 
say that reason, judgement and will are controlled by the objective brain.

By admitting the existence of this duality we shall be able to understand the meaning of brain control.

This duality is little to be noticed in a man whose brain is in a healthy state, as his ideas or sensations are the result of the working of the two brains, and he does not distinguish the working of the one brain from that of the other.

In a great number of nervous illnesses this duality is at any rate marked, and the sufferer is generally more or less aware of it.

Some have assigned to the subjective brain the origin of certain cases of neurasthenia, but it seems more probable that this must be looked for in the want of balance and unity between the two brains; it is to their proper correlation that a man owes his mental health, and his illness is due to the more or less apparent separation of the objective from the subjective brain.

It would seem at first sight as though perfect balance should depend on whether the objective and subjective brains are of equal power; as a matter of fact this is of no vital consequence, as either brain may preponderate in a perfectly 
balanced individual, and the subjective brain may, in some cases, be found to be more fully developed, especially in nervous persons, though there may be no signs of illness. All that is necessary is that there should be sufficient brain control.

DEFINITION OF BRAIN CONTROL.

Brain control may be defined as a faculty which is inherent in a man in a normal state of health, and keeps the balance between his two brains. When we speak of normal brain equilibrium we mean that every idea, impression or sensation is controlled by reason, judgement and will, that is to say, that these can be judged, modified, or set aside as required.

A man in a normal state of health is not fully conscious of this faculty; he realizes that he has control of his brain, but does not at all understand how this control works; on the other hand, a neurasthenic perceives it more clearly, and realizes that he lacks something; that "something" is brain control.

Every idea and sensation is "focussed" by this brain control, which also acts in certain cases as a check, regulating the psychological and even (as we shall see later) the physiological functions of the brain, controlling actions 
as well as ideas. The brain control of a man in a normal state of health is automatic, that is to say, it acts of its own accord without any effort of the will, and, moreover, develops with age and education. It may therefore be said to be the natural attribute of a healthy man.

This faculty dominates the whole life of the individual, and it may even be said that perfect health is impossible without this brain control; we are, of course, not speaking of cases where there may be a temporary lack of brain control, as, for instance, in a fit of anger.

We have seen what brain control should be, let us now see what is meant by lack of this control.

Lack of brain control. It is easy to imagine the state of one lacking this regulating faculty; his uncurbed brain would, without a controlling power, be indeed in a state of anarchy. A prey to every impulse, subject to all fears, unable to reason or weigh an idea, forced to receive all the impressions of his subjective brain, he is nothing but a wreck, doomed to a life of suffering.

Complete lack of brain control is exceptional among the cases with which we are now deal-s ing; what we find more frequently among 
neurasthenic persons is insufficient or unstable control.

Insufficiency or instability of control. In the case of insufficiency, brain control exists as a faculty, but has not sufficient effect, either owing to its lack of development or the existence of certain defects. The objective brain in such a case has not sufficient power over the ideas and impressions.

The sufferer will judge and reason in a normal way, and will nevertheless be dominated by ideas and impressions which he himself recognizes as absurd or exaggerated, and over which his will has no power; this is the typical neurasthenic.

The phenomena of instability of control are in the main the same; in fact, the sufferer's state of health is continually changing from good to bad, and that for no evident reason. These changes recur from time to time; a gay mood may, for instance, be succeeded by a fit of depression, and, whether it be his health; temper, or ideas, all are subject to great variation.

Between the want of brain control and its insufficiency there are an infinite variety of degrees, giving to each case its own characteristic.

In the diagnosis and prognosis of the illness 
these differences are of interest, but it is quite unnecessary to describe them in detail, for in practice it is enough to know whether the brain control is sufficient or not.

EFFECT OF INSUFFICIENT BRAIN CONTROL ON THE IDEAS, FEELINGS, AND ACTIONS.

Let us now see the effect of insufficient control on the ideas, feelings and actions.

We will consider what must necessarily be the effect on the brain of a medley of controlled and uncontrolled ideas and sensations.

It is very evident that even if the insufficiency be little marked, a vague discomfort will be caused to the patient by the feeling that he is not cognizant of some of his ideas, or that he cannot define them clearly enough. $\mathrm{He}$ is also often troubled and even distressed by a feeling of being only half awake and in a sort of halfdreamy state from which he cannot escape.

If the insufficiency is more developed, the symptoms increase proportionately; he no longer suffers from a vague feeling of discomfort, but from a sensation of painful confusion, of a whirl of unconnected and uncontrolled ideas.

The uncontrolled idea will therefore always be unconnected, less defined, and less clear; 
it may be repeated indefinitely, or be, so to speak, fixed in the brain and independent of will control.

Sometimes it really; undergoes serious changes for the worse, when, unknown to the patient, it becomes exaggerated, altered, or completely transformed.

The chief defects of insufficient brain control are exaggeration or deformation of the ideas, also a want of preciseness and clearness.

We find the same phenomena in the feelings, as these are often indistinct or fantastical, with a tendency to be magnified inordinately.

The actions have the same defects. They are indeterminate, seldom considered, and always performed in a semi-conscious condition. As the idea of the action is too indistinct, the sufferer forgets what he wishes to do, or is unable to complete what he has begun.

$\mathrm{He}$ is only dimly aware of all these results of insufficient control over his ideas, feelings and actions, and he accepts them without realizing that they are nevertheless the origin of the most distressing symptoms of his illness.

In spite of the importance of these results, we here only indicate them briefly, for we shall have to deal with them more fully throughout this treatise. 
EFFECT OF INSUFFICIENT BRAIN CONTROL ON THE BODILY ORGANS.

We have already explained that brain control dominates the psychological and even the physiological life of man. This fact is proved by all the organic troubles afficting those suffering from neurasthenia.

It will, of course, be allowed that the organic equilibrium is one with that of the brain, or that these are certainly nearly related.

It is equally certain that there exists a control of the organs intended to ensure their regular working, as well as a cerebral control, that both are subject to the same laws and governed by the same causes, and that they produce the same effects in their respective spheres.

Every defect in the brain control will therefore of necessity react in the organic sphere; sometimes, even, the organic symptom becomes the essential phenomenon of the illness, and the psychical phenomenon takes a second place.

In such a case some particular organ is affected by this insufficiency; for instance, the stomach or intestines (nervous dyspepsia, enteritis) or a system such as the vascular, nervous, or muscular system. In every case the two first of these systems are more or less affected. 
and vaso-motor troubles and pains occur in every case of neurasthenia.

The organs of the senses are equally affected, and troubles of hearing and sight are the most frequent.

The genital organs are often the seat of very obstinate symptoms.

As soon as an organ undergoes any marked change owing to insufficient control, the purely psychical symptoms appear to diminish, and the sufferer attributes all these troubles to the affected organ. This diminution is really illusory, for the symptoms are only disguised, and they reappear with the same intensity as soon as there is an improvement in the organic troubles.

\section{BRAIN CONTROL IN CASES OF NEURASTHENIA.}

We have defined what we mean by brain control, and have described its defects and the results due to its insufficiency.

We will now apply these facts to the treatment of neurasthenic persons.

If in this connection we only treat of neurasthenic persons, it is because they appear to typify a lack of control, since they lend themselves more than any others to the training. 
It must be admitted that the objective and subjective brain of a neurasthenic person are normal and are in no way organically affected; these conditions are essential for comparative success in their training.

In all cases of insanity and purely mental illnesses there exists more than insufficiency or lack of control, and though some of the same marked changes as occur in these latter are also to be found in cases of hysteria, it cannot for that reason be said that this illness is only due to a defect of control. It is of so complex a nature that it is difficult to give the instability of brain equilibrium as its absolute cause.

On the other hand, in a case of neurasthenia, even the least prejudiced observer cannot but recognize, in every symptom, the undoubted existence of an insufficiency of control, and the truth of the saying that "every neurasthenic lacks control" must be admitted.

This conclusion may appear hasty, but we will try to prove it by analyzing some psychical symptoms that are to be found in everybody suffering from neurasthenia. 


\section{NEURASTHENIA.}

WE cannot here give a detailed description of the forms and symptoms of neurasthenia, nor shall we attempt to do so; that would carry us too far and would, moreover, exceed the purpose we have in view.

Our principal aim is to examine them from the point of view of brain control, to look in their etiology, their progress and their symptoms for whatever bears thereon and for what can be accounted for by an insufficiency of control.

ETIOLOGICAL CAUSES.

We will divide these into :

I. Primary causes.

2. Secondary causes.

Primary causes. We will first speak of heredity, for we shall always find that the ancestors of those suffering from neurasthenic illnesses were affected with the same troubles, 


\section{2 TREATMENT OF NEURASTHENIA}

or by more or less pronounced nervous symptoms.

It should be mentioned that this nervous heredity is not so much responsible for neurasthenia as for producing subjects liable to suffer from that illness.

From the point of view of brain control let us note that the nervous heredity either hinders the progressive development of the faculty of control which, in the course of nature, takes place from a certain age, or gives it a certain instability.

Every form of intoxication diminishes the control in the same way.

Among the secondary causes the most important is either a mental shock which abruptly stops the brain control, or any cause which in the long run wears it out; such as sorrow, or prolonged and excessive worry in work. We must also note surgical and other traumatisms.

FORMS OF NEURASTHENIA.

These can be divided into two kinds :

I. Essential.

2. Accidental.

One might also add to these a well-marked recurring or intermittent form. 
Essential Form. This begins in youth and increases steadily with slight remissions until it becomes chronic, generally at an adult age.

It is characterized by its insidious or slow beginning, steady progress and bad prognosis.

Accidental Form. In this form the beginning is abrupt, the sufferer, after appearing to be in a state of perfect health, is suddenly completely prostrated, sometimes in a single night, or else in a very short space of time.

This form does not advance progressively; but the most acute symptoms are immediately apparent.

It is most frequently the consequence of a mental or traumatic shock, which comes on very suddenly, but if due to over-work it begins rather more slowly.

Cases of this accidental form are more easily cured.

The intermittent or recurring form. We add this third form, for it is fairly typical.

Its beginning is rather sudden; without any apparent reason the condition of the sufferer seems to become in a few weeks very serious, and this state lasts some weeks, or months, then suddenly he feels cured and able to resume his ordinary life and occupations.

This period of apparent good health generally 


\section{TREATMENT OF NEURASTHENIA}

lasts some months, or even years, then a fresh attack occurs with few or no premonitory symptoms. This form may occur periodically, in which case there are generally one or two attacks a year.

The sudden return to health which satisfies a sufferer and his friends is nevertheless more apparent than real, for when his brain is carefully examined during these periods it is always found to be in an over-excited state which could not last indefinitely, and according to its intensity is bound to bring on a relapse sooner or later.

In spite of the return to health the prognosis of the intermittent is no better than that of the essential form.

These three forms, which are so dissimilar in their causes, their beginnings and their course, do not differ materially if they are examined from the point of view of defect of brain control.

In the essential form we have to deal with a case of arrested development of this faculty, whereas in the other forms it is a question of the instability of this control; the three forms are in reality only three degrees of insufficiency.

As regards the prognosis, it is natural that the check in the development of brain control 
hhould render a cure more difficult. It is no ynger a question of recovering a faculty which y as simply disappeared as the result of shock or atigue, but it must, so to speak, be entirely :reated, which will necessitate long months of itruggle and perseverance on the part of the iufferer.

Instability of the intermittent form should be asy to correct, but here we have to contend with another factor, in that the sufferer only submits with difficulty to strict treatment, as he already knows that he will again feel well without any effort on his part; it is true that this feeling of good health is very artificial, as a relapse is inevitable. 


\section{PSYCHIC SYMPTONS.}

THE psychic symptoms may be divided into two groups, the first of these comprising the early symptoms, being the latent period, when the brain control is already insufficient, though not permanently so.

The second comprises the chronic state when the insufficiency is more complete and permanent.

In their latent period the symptoms are hardly pathognomonic and often very hard to trace.

The physician has very little chance of seeing them, for the patient does not complain of them and does not put himself under treatment; he is in fact only a subject for neurasthenia, and as this period may last for years without the illness becoming worse, it is very seldom that it comes under the physician's notice.

It is, however, very important that it should be known, for, at the outset, insufficiency of 
control is very much easier to cure, and it would not be difficult to anticipate and to prevent the insufficiency becoming permanent.

During this period, training is of the highest importance, and however little these latent symptoms may come under the notice of the physician, he can at least, on becoming aware of them, warn the patient's relations and thus be the means of saving much suffering.

Though the symptoms themselves have no distinct character, and though they hardly differ from those to be noticed in a case of pure nervousness, still, nevertheless, when taken as a whole, they do not deceive a careful observer.

The earliest symptom of the latent period is an exaggerated sensitiveness; its distinctive characteristic is its want of permanency; as in simple nervousness, the character is changeable, gay or morose, expansive or self-centred all for no obvious reason. Cross-question the sufferer and he will not be able to describe his condition, but will speak of moral uneasiness and sometimes of an undefined fear or of vagueness in thought.

He often allows himself to get into a kind of dreamy state, a semi-conscious condition which is by no means disagreeable to himself, but he does not realize the danger of it, nor can he 


\section{I8 TREATMENT OF NEURASTHENIA}

shake it off easily. The longer this condition lasts the worse do the symptoms become; such as, for instance, apathy, fatigue, and want of interest in life.

Should this dreamy state not exist there will at least always be a great uncertainty of thought, which is never fixed on any definite point, and causes a state known as "Brain wandering."

This latter which is as characteristic of uncertain control as the dreamy state, is not so troublesome, and may last a very long time without becoming worse; but, however temporary it may be, it is bound to bring on brain fatigue, and the consciousness of this instability causes indecision and want of confidence.

The sufferer reflects on everything he does, and reasons on all his thoughts without reaching a definite and practical decision. He lives very little in the present and his thoughts always turn to the past or the future.

We must bear in mind that all these phenomena are transitory, and recur over and over again, leaving the sufferer perfectly normal between the attacks; they are very character. istic of uncertainty of control. All these phenomena are, moreover, to be found in chronic cases with this difference, that the patient suffers 
greatly and no longer has any periods of intermission.

It has been said that this latent period is of no definite duration, it can last for years and often suddenly becomes chronic as the result of a very slight mental shock.

SYMPTOMS OF THE CHRONIC STATE.

It is easy to realize that the symptoms of the chronic period arise one from the other, and that they merely follow each other in regular succession, from instability to permanent insufficiency of control. There exists, moreover, an important phenomenon which distinguishes the latent clearly from the chronic period, and consists in that the sufferer becomes more and more conscious of the state of his brain, which feeling, although it is often ill defined, brings about a very typical sort of fear and anxiety. It is also owing to this same feeling that a symptom, while hard to tolerate in the second period, is easily borne with in the first.

This explains how something of very small importance can be immensely exaggerated and often leads to a fit of despair, the sufferer losing sight of the real cause of his crisis and being only conscious of the insufficiency of control.

When looked at from this point of view, all 
the symptoms of neurasthenia are easily understood; they are not imaginary; they are real and are the necessary result of the abnormal working of the brain.

All the chronic symptoms of neurasthenia may thus be said to be due partly to the extent of the uncertainty of control, and partly to the recognition by the sufferer of this uncertainty.

Let us now see what happens when the symptoms of the latent period become worse.

We will consider the sufferer in this dreamy semi-conscious state which is not in itself one of ill health, for it is found in a healthy man when in a state of repose; but in his case it is voluntary, and he can either dream or not at will. At the beginning of the latent period this also happens, but gradually the sufferer gets into the habit owing to indolence of the brain; he tries to overcome it, but cannot, and is even afraid of doing so as the effort becomes painful. $\mathrm{He}$ therefore lives more and more in himself and apart from outside life; hence that form of unhealthy egotism which is all-absorbing and makes him a nuisance to his friends. He loses. all interest in surrounding things, and sees them only more or less dimly. He has no feeling except for his own personality, which he often detests, but from which he cannot escape. 
We have already said that he suffers through trying to overcome these feelings, and it is a curious fact that the return to a healthy state of control is only attained by a sort of wrench and with pain, which the sufferer fears. On the other hand, he also knows that this dreamy state cannot continue indefinitely, but that it necessarily ends in sadness, depression and great distress; he is, therefore, between these two alternatives, and devoid of will, strength or courage.

The instability of thought, which we have calied "brain wandering," is not troublesome at the outset except in that it renders all work difficult, but it is another question when this condition is prolonged and becomes permanent. The unending work tires the sufferer, and the mass of ideas ever crowding day and night into his brain overpowers and distresses him.

He no longer feels master of himself, but is like a rudderless ship in a storm. Owing to their number and also to fatigue, his ideas lose their true proportion and become vague and confused, and the result is utter despair.

The over-excited state of the brain, which he suffers from at the outset, becomes proportionately worse, and results in fits of anger and 
of causeless despair which are followed by prostration, sadness and depression.

When this want of control is realized, there result a whole series of diverse feelings which we will now enumerate.

Feelings of inferiority. The sufferer loses confidence in himself, he feels unfit for any serious work, and often even for any conversation, for which reason he avoids his fellowcreatures. He magnifies and is afraid of everything. The slightest change in his habits or the smallest task may bring on an attack of great distress, simply because he does not feel himself capable of the work.

$A$ continued state of anxiety necessarily results. This feeling, which is so trying to the sufferer, is due to the same cause; his life is passed in foreseeing troubles. $\mathrm{He}$ is never quiet or happy, but is always conscious of a dread of the present, and the fear of the future looms before him.

Even when life does not appear so gloomy, there is at any rate anxiety and painful distress; the sufferer does not know what he wants or what to do. If he does anything, he is sorry for it, and matters are still worse if he does nothing. 


\section{GREAT DISTRESS OF MIND (Fr. ANGOISSE).}

From anxiety to this state of distress there is only one step, and that a short one. This is one of the most typical symptoms resulting from lack of control. It is also the most violent, which may drive the sufferer to any extreme, and which often seems to be unexplainable. It may cause a physical pain as well as mental suffering, and is peculiar to every sufferer. It is something he cannot realize, which drives him to despair and madness. The suffering caused by it shatters the most resisting brain, and is the pain which is least bearable and most feared.

Sometimes the sufferer traces this feeling to a bodily organ, even, for instance, to the heart, stomach or intestines. This kind of pain is not acute, but is dull and causes the strangest and most varied feelings.

\section{LACK OF WILL (Fr. ABoulie).}

It may be said that every neurasthenic lacks will power; in fact there exists every degree of this, from the undecided man who puts off an action indefinitely to the one with no will power whatever.

But we shall see later that the want of will is more apparent than real, and that it is more a 


\section{TREATMENT OF NEURASTHENIA}

question of want of its use. Whatever it may be, the result is the same. Every idea, every act of will causes a sensation of fear in the mind of the sufferer, he foresees that all effort is in vain, and he is paralyzed and fettered by doubt. It is the fear of using his will that deprives him of the power of doing so, for every effort is painful, and every action causes great distress.

Fears and obsessions. These symptoms are persistent in the chronic state. The fear of a word, feeling or thing which often haunts a neurasthenic is always due to a notion that the idea is not subject to his will, and that he cannot put it aside or shield himself from it.

PHYSIOLOGICAL (ORGANIC) SYMPTOMS DUE TO INSUFFICIENT BRAIN CONTROL.

In addition to the psychical symptoms which we have just described, there exists a whole series of physiological symptoms which are directly connected with the want of brain control. The organ affected often reflects the state of the brain so accurately, that it shows signs of the same fear, distress and lack of will.

We will not consider all the symptoms which may be produced in the organ in question, for they are not peculiar to the want of control, but are due to the bad working of the organ. 
This bad working of the organ comes from the nervous system on which all the anomalies of brain control naturally react.

The vascular system seems to present the most peculiar reactions; under the influence of the vaso-motor nerves the organ affected becomes anaemic or congested, and its secretions increase or diminish at the least psychical influence.

All systems may be affected; most frequently so the digestive and genital-urinary systems, the latter especially in the case of a man.

The organs of the senses present certain peculiarities which should be examined.

Sight. All the anomalies of sight are exaggerated in persons lacking control ; objects, like ideas, become indistinct and confused, and that without the organ being impaired. One might say that the objects are impressed on the retina without reaching the brain; psychically speaking, the sufferer looks without seeing, as also he may be said to listen without hearing.

Hearing. If the sight is dimmed, the hearing is usually affected in the contrary sense. There is, in fact, often an excessive excitability which makes the sufferer aware of the slightest noise, and is very frequently a cause of insomnia. 


\section{TREATMENT OF NEURASTHENIA}

Touch. The hand appears to be conscious of anything it touches, but the sensation is obliterated before reaching the brain, as the latter is not sufficiently conscious of what is touched.

We have endeavoured to point out this mental fact, for the physiological symptoms which we have just described are of little importance in themselves, but for the treatment it is necessary to know their psychical cause. 


\section{THE NECESSITY OF TRAINING THE BRAIN CONTROL.}

From the foregoing chapters we have seen that the essential cause of all neurasthenia is due to instability or insufficiency of what we call brain control.

This fact appears sufficiently proved to enable us to base on it the treatment of neurasthenia Mere medicine cannot be expected to restore a lost faculty of the brain, or to perfect an undeveloped one; we must, therefore, only hope to attain such a result by some means of psychotherapy.

Let us now shortly review the different forms of treatment, not in order to criticize, but in order to decide on the reasons for the training.

Hypnotism. Suggestion. This method has already led to such successful cures by experienced doctors, that its efficacy cannot be denied. It has often proved wonderfully suc- 


\section{8}

TREATMENT OF NEURASTHENIA

cessful when it was a question, from the psychical point of view, of relieving a patient or of removing a symptom (constipation, indigestion, etc.), while inspiring him with courage and hope.

But if it is a case of retraining the controi during hypnotic sleep or by suggestion, the result is only transitory, as the patient always relies more on the doctor than on himself, and prefers the easy suggestion to a personal struggle.

Efforts have been made to attain the same object as we have in view by employing other methods of psychotherapy, such as the training of the will, which is Dr. Dubois' system, and while opening up a new field for the treatment of nervous illnesses these have undoubtedly been attended by results surpassing all that could have been hoped for. In view of the success of these efforts, the question may be asked, why should we look for anything more, and where would be the advantage or necessity of another treatment?

In answer to this let us quote what has ofter been said by a patient who has been treated but not cured: "I already know all that you are telling me, I really want to carry it out but cannot; please show me how to." 
TRAINING THE BRAIN CONTROL 29

This criticism really has a basis of truth which annot be denied. It is not always enough to'all the patient what to do, he must be shown ow to do it; that is the rôle and purpose of ie training.

We must remember that a patient lacking lontrol is like a child who has never walked; uㅏㄹ th teach him his first steps and support him orn his walk; we will afterwards correct his ministakes.

In this anomaly of brain control we must do nore than concern ourselves only with the vrong ideas which can be corrected by reason. The different changes which we see produced py insufficient control force upon us the conriction that not only has there been a change $\mathrm{n}$ the ideas but in the working of the brain tself, and that there is, therefore, something abnormal in the working of that organ. This imperfect action can be corrected by training, but not by reasoning alone.

HOW TO CONTROL THE BRAIN.

When coming to the conclusion that it was necessary to train brain control, we stated that we should show the patient what to do; that is, in fact, the knotty question which is of special importance to the doctor. Before, therefore, 


\section{TREATMENT OF NEURASTHENIA}

beginning to study the question of training, our procedure must be explained in order to show. the patient what he should do.

As far as was known to science the working of the brain appeared to be under no direct control of the physician, that is to say, the latter had no means of verifying the statements of his patient with regard to his brain.

Struck by this hiatus, we endeavoured to find some simple way to overcome the diffculty.

It seemed very surprising that symptoms, which were sometimes so intense, could not be perceived (verified) by external observation. The cerebral pulse certainly gave indications, but these seemed to be of no practical: use.

We have, however, found, contrary to the opinions generally accepted, that after a certain amount of training, the physician's hand can, when placed on the patient's forehead, give him sufficiently exact indications as to the working of the latter's brain.

This statement will, no doubt, be received: with great scepticism, for it is certainly difficult to believe that the movement of the brain can be noticed through the skull; though we will not try to explain it, all that can be said is that 
TRAINING THE BRAIN CONTROL 3I are undoubtedly exists a repercussion which "n be felt by the hand; this gives a series of lsations producing the effect of an undulation of a peculiar vibration.

No special gift or particular sensitiveness the hand is required in order to perceive "ese movements; many of our patients have, th practice, been able to perceive them. Those wishing to try the experiment should oceed as follows.

Ask a friend to follow attentively the ticki $k$ of a metronome or, better still, to repeat it entally. If you put your hand on his foread either flat or vertically, you will notice a nute shock or beat on the right and left side ernately, which keeps time with the tick:k.

With increased pace of the metronome the ats become quicker; in like manner the ats will correspond with it on its pace being creased.

Should the subject's mind wander, no beat 11 be noticeable at that moment, but there 11 be a check, and you will perceive a ange in the vibration. The thoughts of e person in question and the feeling perived by you, therefore, correspond one with other. 
It is possible that your first attempt will not give you a sufficiently definite result, but with. a little patience the vibrations will gradually: become distinctly noticeable.

We only mention this fact as a simple experiment, and will give more complete and scientific proofs later.

For the moment we will allow that the sensation perceived corresponds to the working of the brain, and that it changes according to the state of the latter, that is to say, that it is easy to notice the difference between a calm and agitated brain, and still more between an ideaor a thought which is under control and one that is not. This fact is a great aid to the diagnosis, and enables the physician to examine the state of the patient.

We in no way pretend by this means to know the thoughts of the patient, but only to what extent they are under control.

With a little practice one recognizes certain changes in the vibrations felt by the hand which correspond to certain conditions of the brain. We will try to describe these, and will use the term vibration or undulation for the sensation felt by the hand. 
ABNORMAL CONDITIONS OF THE BRAIN.

There are three principal types of the want of control:

I. State of torpor.

2. State of over-excitement.

3. State of tension.

The first of these is characterized by a diminution of the sensation felt by the hand, the reactions are irregular and slower, and the brain is felt to be less active, heavy and without energy.

The state of over-excitement, on the contrary, shows strong vibrations, but these are disorganized and different from a normal vibration which is always more or less regular.

The state of tension is always painful, giving the feeling of the neck being gripped or of compression of the temples. The patient has the feeling that his brain is blocked or contracted. At the beginning this feeling is a phenomenon of natural defence against the sensation of great distress, or simply because the patient is more or less aware that his brain is not under control. It is, therefore, always to be found in all cases of neurasthenia. This momentary symptom may in certain cases 


\section{4 \\ TREATMENT OF NEURASTHENIA}

become persistent and create a particular type.

This tension or contraction is not limited to the brain, but may occur in any part of the body.

The muscles are at first more or less contracted and sometimes painful, walking becomes difficult or even impossible. The balance is uncertain. The oesophagus, stomach and intestines also become contracted.

-When confined to one arm or leg this muscular form easily leads to errors in diagnosis. The physician may think of hysterical contraction, and if the tension is more general, of a lesion of the brain or of the spinal column.

The brain tension is immediately discovered on examination; the vibrations are in a state of tension.

There is no freedom in the reactions which are very rapid or appear to have ceased altogether.

NORMAL AND ABNORMAL VIBRATIONS.

We have seen that it is possible for the hand to discern different abnormal states of the brain. With a view to helping those who would like to try our experiments for themselves, we will now describe the most characteristic forms of vibrations which can be felt in this way. 
We will first consider an absolutely healthy brain.

Here we find a pulsation giving, according to the state of the brain, about 35 to roo beats a minute.

The vibrations are slowest when the brain is calm, but increase as it becomes animated. The waves of vibration also vary in length and intensity. When it is a question of testing the will power it will be found that the beat is quicker and more defined.

In spite of these variations there is a certain rhythm and regularity in every healthy vibration which is not the case with abnormal vibrations, as these are always irregular.

Very regular vibrations are never found when examining the brain of a neurasthenic person, even when apparently in a perfectly healthy state.

In such a case the vibrations may at first seem to be normal, for a few. more or less rhythmical beats are to be felt, then a state of sudden confusion in the brain arises which produces a series of disordered beats, after which all becomes calm, but soon the confusion reappears. On questioning the patient he will tell you that an idea passed through his mind or that his thoughts were wandering. He may 
sometimes say that he cannot explain it, but the physician may be quite sure that his brain was for the moment not under control.

When the patient is possessed by some idea or perhaps only over-excited, the beats become too rapid to be counted; a violent beat will be noticed, followed by others almost imperceptible, but never a series of vibrations of equal length and intensity.

The state of great distress in a patient is merely a much more accentuated form of the over-excited state; the vibrations are still more marked and disorganized, and soon give rise to a feeling of utter despair.

The afore-mentioned state of tension also presents the same irregularity.

The above are the most important forms resulting from want of control, and on recognizing them the physician may attempt our: method of training the brain.

\section{HOW TO MODIFY ABNOR.IAL VIBRATIONS.}

Once we have admitted the existence of abnormal vibrations peculiar to a want of brain: control, we are forced to conclude that the actual working of the brain is changed by every: deficiency of control. This material conception of neurasthenia is very important and must not 
be overlooked in the treatment, for in recognizing this fact we learn that the training of brain control cannot be a perfect success unless the patient also manages to change the working of his brain and to acquire normal, in place of abnormal, vibrations.

The first thing we must ask ourselves is, how is this to be done?

We already know that they are caused either by instability or by insufficiency of control; but the mere knowledge of how they are caused is not enough to teach us how to carry out the training.

There are other causes to be sought for which will give us the key to the enigma.

When examining a patient's brain, an abnormal vibration will very often be felt to change, e.g. to beat in time and with the regularity of a normal vibration.

To what are these changes due in an abnormal vibration? We may say that the following are the three chief causes.

I. If the patient suffers merely from instability of brain control, it will generally be sufficient if he becomes conscious of what he does and thinks.

2. If the brain, to a certain extent, lacks self control, it will not be enough for the patient 


\section{8}

\section{TREATMENT OF NEURASTHENIA}

merely to become conscious of his actions; he must be able to concentrate his mind on each of his acts and ideas.

3. The third and most important factor which may take the place of the other two, consists in the use of will power. The patient's actions or ideas must either be voluntary or he must feel that they are subject to his will.

The control and working of the brain depend on the three above-mentioned conditions.

The patient must have enough power of $i$ concentration and will power, and also be thoroughly conscious of what he does in order to be able to control himself. 


\section{TREATMENT.}

In dealing with this question we must bear in mind the teaching of the foregoing chapters and examine the cure of neurasthenia, both from the functional and psychical point of view.

We must first modify the working of the brain by teaching the patient how an abnormal vibration can be made normal, and then train his control by means of psychic treatment.

Though these two aims are in themselves inseparable, we distinguish between them chiefly with a view to making our meaning clear.

\section{FUNCTIONAL TREATMENT.}

It has been seen that all cases of instability or insufficiency of control are characterized not only by psychic, but also by functional, changes; it is, therefore, quite natural to try to improve the abnormal working of the brain in the same way as we try to improve an abnormal idea. 


\section{0 TREATMENT OF NEURASTHENIA}

As for the patient, this material conception of his illness is also of use to him, for he needs something more tangible than the mere idea of it which he already knows he cannot get the better of. By giving the patient the qualities he lacks we can show him how he can modify an abnormal vibration, or how a controlled can take the place of an uncontrolled brain.

The object of the following mental exercises, which supply the necessary qualities of control, are intended to give the patient the will power, concentration and consciousness which he lacks. They are also types of normal vibrations, and by their means we shall attain our two objects.

Insufficiency of control is not only found in thoughts but also in acts. It is through these latter that we shall begin to train the control, for it is easier at the beginning to teach a patient to control some movement or action than to control his thought.

\section{CONTROL OF THE ACTIONS.}

When training the brain, control of the actions must be taught first, this being the simplest means to the end desired; at the outset this method may often appear childish, but the results are nevertheless very evident. 
When observing the actions of neurasthenic persons in daily life, one is immediately struck by their vagueness and want of precision. One generally feels that their thoughts are elsewhere or that their attention is never fixed on anything they think or do. The conception of both their thoughts and actions is always feeble, and the lack of any definite purpose is very noticeable.

For instance, a person suffering from neurasthenia may go to fetch something from his room and when he gets there he no longer knows what he wants; if what he looks for is locked up in a drawer, after he has taken it and gone out of the room he will not remember whether he has relocked the drawer or whether he has shut the door after him, etc., etc. He will have done everything in a semi-conscious state, inattentively and with no fixed purpose, he was unable to keep his mind on his original intention of fetching something.

It is easy to imagine how trying this state of mind may be in practical life; all the abovementioned semi-conscious actions react moreover on the brain, the mind is fatigued by the effort to remember what it has done, and this constant uncertainty distresses the patient and tends to make him lose confidence in himself. 
We will not ask the patient to note mentally all his daily actions, for that would be impossible, but to try every hour to do a certain number of things in a definite manner. By this constant repetition of controlled actions the patient's brain will in a relatively short time acquire a certain habit which will be of the greatest use to him.

Method. Let us first take a simple movement, for example, bending the arm which we will ask the patient to do. To be well under control the movement must be sufficiently conscious, concentrated and voluntary, that is to say, the patient must know what he is doing, he must exert enough strength to do it and he must keep his mind on the movement until accomplished. In order to control this movement place the hand on the patient's forehead when, if the movement is correct, a uniform vibration will be felt, whereas, if the movement is not sufficiently under control, the wave of vibration will be broken.

When the patient is shown what is wrong he easily realizes it and gradually corrects his mistakes.

As it is impossible to concentrate the attention for long on the movement we have described, the patient should be asked, especially 
when beginning this exercise, to continue the movement for only a short time.

Control in walking. Tell the patient to take four or five steps, and while doing so, to have the definite sensation (in his brain) that he is putting his right and left foot forward alternately. Then ask him to realize clearly the movement of his leg and then of his whole body, teaching him at the same time to know whether the movement is sufficiently supple and easy. He will soon see that he will be very much less tired if he controls his walking from time to time.

In most of these actions the vibrations of the brain cannot be felt by the hand, but, with a little trouble, the physician can notice what the patient is doing wrong. The latter must also give his entire attention to this exercise, or if what he does is not under complete control he will not benefit from it in any way.

In order to obtain as perfect results as possible, we should not content ourselves only with control of the movements, but should endeavour to make the actual senses as conscious as we can.

Touch. The patient should take some object in his hand and determine mentally the 


\section{TREATMENT OF NEURASTHENIA}

exact sensation of its form, weight, temperature, consistency, etc.

Sight. As we have already said, the person lacking control often looks without seeing; in order to correct this the brain must be taught to pay attention to everything that strikes the eye, and to see all things clearly and distinctly. As an exercise pass some object, say an engraving, quickly before the patient's eyes, and then ask him to describe what he has seen.

Hearing. In order that the patient's hearing should become fully conscious and should lose the habit, as it were, of listening without hearing, he ought to accustom himself to defining the sounds he hears, and later be able to concentrate his attention entirely on one particular sound, for instance, on the noise of a passing tram, or the ticking of a watch, etc. It is very important that he should not feel himself obsessed by some particular sound which often happens, but that he should be able to listen only to what he really wishes to. It must once more be said that all these exercises should only be of short duration, say for a few seconds, and that they should be varied as much as possible. 
VOLUNTARY ACTIONS.

For the sake of convenience in dealing with the question of treatment, voluntary actions may be put in a class apart. While every conscious act is of course at the same time a voluntary one, as it is due to an effort of the will, we must make the following distinction.

When we ask the patient to do something consciously, we simply mean that he should be cognizant of performing the act, that he should, for instance, feel that he is bending his arm; but in the case of something done voluntarily the patient only primarily realizes that he is making use of his will; he feels that he will bend his arm.

If, on telling a patient to get up, he does this consciously, the idea in his mind will be, "I feel that I am getting up"; if he does it voluntarily, it will be "I will get up."

Though this may appear rather a subtle distinction, it is a useful one, for it is the first step in training will power.

If the hand is placed on the patient's head a difference in the vibrations will, moreover, be noticed; in the voluntary act the undulation perceived will be more accentuated than in the conscious act. Let us then teach the patient 


\section{TREATMENT OF NEURASTHENIA}

to make voluntary actions distinct from those which are simply conscious.

$\mathrm{He}$ should, for instance, be told to get up in the morning and to go to bed voluntarily; to go out of the house and to come in because he has made up his mind to do so.

PSYCHIC EFFECT OF CONTROL OVER THE ACTIONS.

Let us now consider what effect the control of his actions has on a neurasthenic person. At first sight it would appear that this continual attention to all daily acts is something quite abnormal, which could only produce some new unhealthy symptom; but this is not so in the case of a person whose brain is not under control. By this continual attention he can acquire a habit which will be very useful to him. If all he does is really well done he will feel calmer, better balanced and more master of himself. When his brain is always concentrated on something definite, it will become less and less troubled. He will regain confidence in himself and his mind will always be under control.

The more carefully the patient tries to carry out the conscious and voluntary acts, the sooner will he perceive that the great effort and atten. 
tion which were so necessary at the beginning are no longer required; what was formerly a labour is now an easy habit, which should gradually become natural and normal.

The patient should understand the importance of this training and carry it out thoroughly, for we have seen neurasthenic persons cured by this simple means; all that can be brought 'zainst it is, firstly, its simplicity, which does not sufficiently impress the patient; and, secondly, the fact that it often takes a long time to acquire the habit.

As regards the effect of conscious and voluntary acts on the abnormal vibrations, it may be isaid that if the act is well done the vibration becomes normal, and that in many cases the leffect lasts for some time. If no change takes place in the abnormal vibration, it is certain that the act was not under complete control. Should the exercises be carried out regularly, the vibrations of the brain must of necessity become habitually normal.

The conscious or voluntary act impresses itself more on the mind, and, the patient remembering what he has done, will gradually regain the memory which he had lost.

A mistake common to all beginners is that of making too great an effort to perform an act 
48 TREATMENT OF NEURASTHENIA

consciously; instead of this, the sensation of an act performed under control should rather be one of repose, for the brain should be possessed by only one idea and feeling, namely, that of the act performed. 


\section{CONTROL OF THE IDEAS.}

$S$ we have seen how to control the actions, le will now pass on to the control of the ideas; ere there also exist three essential conditions, $\hbar$ was the case with the control of the actions.

I. The idea should be conscious.

2. The patient should be able to concentrate is mind on the idea.

3. The idea should be subject to the will.

THE IDEA SHOULD BE CONSCIOUS.

By this we mean that the patient should lave a thorough knowledge of his idea, a Inowledge which is natural to the normal mind, lut only exists partially in one that is unconrolled. It must be recognized that in a case f neurasthenia the brain is generally in a state $f$ confusion, and ideas follow each other in uch a rapid and unconnected manner that the atient cannot keep count of all that come into 
his head; they are, moreover, seldom clear or prècise, and can only be expressed by him with difficulty.

This unconscious state of the brain is very variable, being sometimes very troublesome, and occasionally very slight, when the patient does not realize its existence.

It can be easily understood that we could not ask a patient to judge, argue out, and put aside an idea or thought, if he is not perfectly cognizant of it. We should, therefore, teach. him this knowledge, and in order to do so we must ascertain the extent of consciousness in the brain.

STATE OF CONSCIOUSNESS.

In order to teach the patient how to become cognizant of his brain, he should be asked to make a rapid examination several times a day. of all his feelings, thoughts, and even of his ideas; this examination may be merely mental, or may, in certain cases, be written down to show the physician. If written down there is: this advantage, that it obliges the patient to express his ideas definitely.

This state of consciousness is the "gnothi seauton" of the ancient philosopher; one lacking control should, more than most people, 
snow himself, not in order to pity himself, but in order to become aware of what is good or sad in his brain. When cured he will understand how his mind works, the abnormal shanges which some thoughts or impressions undergo, why he becomes distressed, and what houghts or ideas cause this distress. He will realize that an uncontrolled idea is like a "udderless vessel, which often takes a different direction to what was intended. He will also see that there are certain thoughts that should je put aside lest they should trouble him again, hat certain ideas must produce certain sympoms, and that the fear of a former pain nearly lways reproduces it.

If the written analysis already mentioned is well done, it constitutes a series of experiences for the patient, who will, after numerous attempts, become convinced of the evils of zertain ideas and of the importance of controlling his thoughts and impressions.

There is also much for the physician to do in showing the patient his faults and how to jvercome them; he will also find in this analysis many hints for his treatment.

The patient should take no notice of all the little worries which preoccupy him, but try to ascertain their cause and origin. This analysis 
52 TREATMENT OF NEURASTHENIA

should be useful and also interesting to him, for in it he will note his experiments and their results.

CONDITIONS OF THE BRAIN.

In order to acquire a fairly complete state of consciousness, the patient should, at the outset, examine the state of his brain.

From the point of view of control, there are two distinct conditions of the brain.

I. Active condition.

2. Passive condition.

Active condition. By this we mean that the brain is normal. This state may occasionally. be found for a very short space of time in an uncontrolled brain, when, from the functional point of view, if examined by the hand, thevibrations are regular, rhythmical and even; if considered from the psychical point of view, the brain may be said to be in a con: scious and controlled state and subject to the will.

This active state might also be described as:? the positive condition, which term would perhaps be better understood by the patient; in this condition he is aware of what he thinks and does, and can carry out what he wishes, 
the brain is therefore without fear, trouble and abnormal ideas.

Passive condition. Every variety of want of brain control is to be found in this condition. Such a brain may be conscious but is never voluntary, that is to say, governed by the will. Psychically speaking, it is characterized by a peculiar receptiveness and is like a door open to all weaknesses, obsessions and fears. All these psychical symptoms only exist in the passive condition, which is, therefore, preeminently an unhealthy one. In order to give the patient some idea of what this passive condition may be, we will here enumerate the principal varieties, starting from the form which most resembles the active condition :

I. The dreamy, semi-conscious and tired state.

2. Brain wandering.

3. Over-excitement.

4. Confusion.

5. Worry.

6. Depression.

7. Great distress.

Each patient typifies one of these conditions, that is to say, that one will suffer more from bver-excitement or confusion, another rather 


\section{TREATMENT OF NEURASTHENIA}

from depression or distress, but nearly all neurasthenic persons suffer from one form or another.

These different varieties have each their peculiar vibrations, and one can, for instance, easily distinguish with the hand the dreamy from the over-excited state, or brain wandering from distress of mind.

The chief use of this classification is to enable the passive state to be easily recognized by the patient. We are quite certain that the great difficulty which a neurasthenic person has to contend with, is that he does not know what is the matter with him, that he does not understand it, and that even if he did he is unable to alter it. Let us then, by making him conscious, give him the knowledge he requires, and, by training his brain, show him the means by which he can cure himself.

The state of consciousness is a condition absolutely essential to a state of perfect control. But it is a curious fact that in certain cases it is enough for the patient to have the functional state conscious, that is to say, that it is enough for him to realize that his vibrations are abnormal, and to modify them by an exercise in order to obtain a cure, without having to think of the idea itself. 


\section{CONTROL OF THE IDEAS}

This, so to speak, mechanical cure will be less perfect than a complete retraining, but it satisfies the patient, because he can overcome his symptoms and feel that he is master of them. 


\section{CONCENTRATION.}

Having explained what is meant by the conscious state, we will now turn to concentration, which is a second quality essential to control.

Definition. Concentration is the ability to fix one's thoughts on a definite object, to follow out an idea without letting the mind wander, or simply to absorb oneself completely while reading or when occupied in an wher work. This ability is never found in those lacking control.

\section{CONCENTRATION EXERCISES.}

First exercise. When beginning it is too difficult to concentrate on an idea. We therefore suggest as the first exercise that some. curve should be followed out in the mind, or if preferred, the figure 8 , or, better still, the mathematical symbol of infinity should be imagined by the brain. 
One would hardly suppose that such a simple exercise would present any difficulty, and yet many patients are incapable of doing it correctly.

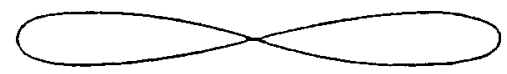

If the exercise is well done, the physician will feel a regular double undulation, if badly done, he will notice interruptions always immediately after the exterior curves, and, moreover, with a little care the patient will notice it himself.

Second exercise. Ask the patient to listen to a metronome and to mentally repeat the ticktack for ten or fifteen times when beginning, and then gradually to increase the duration of the exercise.

Third exercise. Accustom him whenever he touches anything to retain the impression of the object for a certain length of time. Concentration of sight, hearing and touch are taught by these three exercises.

Fourth exercise. Concentration on a certain object. In this exercise the patient should try to determine in his mind the exact feeling of his right hand, then of his left, then of the right and left foot alternately, afterwards thinking of 
58 TREATMENT OF NEURASTHENIA

his elbows, knees, ears and different fingers, etc.

In order to determine the exact feeling, the patient is as a matter of fact obliged to fix his thoughts actually on the object in question, and the advantage of this exercise is that he can himself tell if he succeeds in doing so. When the concentration is well done it will, after a few days' practice, give a peculiar feeling which he will easily recognize, namely, sometimes a tingling, sometimes a slight beat, or a feeling that the blood is flowing towards the spot in question.

The vibration felt by the physician with the hand is more accentuated on the right side when the patient thinks of his right hand and vice versa when he thinks of his left.

Fifth exercise. The physician should put his finger on some muscle and ask his patient to concentrate his mind on the exact spot touched, when, if the concentration is good, a slight. muscular contraction will immediately be felt; it is often necessary to wait a few seconds in order to be sure of this feeling.

The exercises which we have described are easy and may be varied ad infinitum; only those most frequently employed are given here. 
Sixth exercise. Concentration on the figure Although at the outset this exercise appears asy, it is often found to be difficult; many atients take weeks before succeeding in doing properly.

The patient should be told to write down the igure $\mathrm{I}$ and then repeat it mentally three times n succession, not allowing any other thought to nterfere. Between each time that the figure I s mentally written and spoken, there should be in interval of repose lasting from half a second o one second, thus :

$$
\text { I, rest ; I, rest ; I, rest. }
$$

During the period of rest it is not necessary :o retain in the mind the vision of the figure $I$.

In this exercise we thus concentrate on what we mentally see, speak and hear, for when speaking mentally we listen mentally, and moreover, perform the act of writing mentally which also employs the brain.

As soon as the patient can do this correctly three times, the number should be increased to four, five, six or seven times in succession; any patient who can do this seven times in succession has quite sufficient power of concentration.

Let us now examine the functional working of the brain during the above-mentioned exer- 
cises. To begin with, it should, by means of the will, be put into a state of complete rest, then the $\mathrm{r}$ should be written, spoken and heard by the mind all at the same time.

The patient should then efface everything from his mind for a second and then start afresh, which really means that he must reconcentrate his mind several times in succession. It is to be noted that if there is no interval of rest between each figure $I$, this exercise presents no difficulty; but in that case it is of little use. Its difficulty is due to the fact that the patient is obliged to gain complete possession of his brain. It is absolutely necessary for the physician to control this exercise, for the patient, when beginning, hardly realizes what he does wrong.

When an act of concentration has been well done, the curve of the vibration may be thus represented :

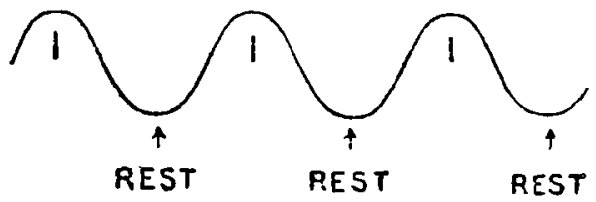

A distinct beat is produced by every $\cdot \mathbf{I}$, which is then followed by a relaxation (French, detente) representing the period of rest. 
When badly done the result may be represented thus:

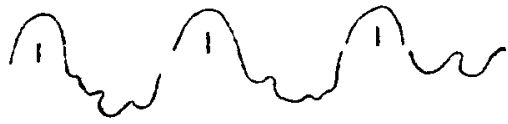

When beginning this exercise it is useful to see the figure I mentally, though we need not attach much importance to this later on; it will subsequently be sufficient if the patient has the feeling of writing, saying and hearing it mentally.

Of course, for this exercise any other number, line or point, might be taken; the reason we have chosen the one is that this accustoms the patient to the actual idea of concentration, that is to say, that in order to be concentrated the mind must be fixed on one thing, one idea and one fact.

The patient will now be able to turn more easily from this form of, so to say, mechanical concentration, to the really psychical form, and for this purpose we recommend him to try and unite all ideas in his mind and to fix them, so to speak, on the one, that is to say, he should say "one" mentally when he feels sure that all his thoughts are concentrated on one idea. 


\section{TREATMENT OF NEURASTHENIA}

He might, for instance, as an exercise, picture in his mind a circle of which all the spokes (thoughts) converge to a one as a centre.

Every patient has his own way of attaining this result; some by imagining that they compress their brain to such an extent that room is only left for one idea, others, on the contrary, eliminate all ideas but that of the figure one.

After a little perseverance the patient is gradually convinced that he is able to concentrate his thoughts, though perhaps only for a short space of time. Even when he can do this, which will of course be of great benefit to him, it is not sufficient, as he must be able to concentrate his mind when he wishes.

This concentration will present greater diffculty, and in order to attain it the patient must accustom himself to overcome all distractions, and he should try, when surrounded by people, and during any noise, to carry out the exercises which he had at the outset learnt in quieter surroundings; in this way he will increase the certainty which he has of being able to concentrate his mind when he wishes to, which concentration is not perfect unless, when in difficulties, he is thus able to overcome a feeling of distress or put aside some fear. 
The patient, having now reached this point, we will ask him to concentrate his mind on in idea.

CONCENTRATION ON AN IDEA.

In this exercise the patient should try to levelop some idea in his mind, to solve a rroblem, to write a resumé of something he las read, or to listen for a definite time to a :onversation or lecture, while allowing nothing o distract his attention, that is to say, while hecking at once any idea irrelevant to the ibject in question.

A practical result will only be reached gradullly and after many failures; in order not to ose heart it should be done for a very short ime at the outset and be looked upon as a imple exercise.

The error most frequently committed by the atient when beginning is that he asks himself $f$ the concentration is successful while doing he exercise; by doing this, which he does lmost involuntarily, he is disturbed and his :oncentration is of course interrupted. He hould understand that his concentration will 1ot really be successful unless he does the :xercise as simply as possible.

The only one of these exercises which can 


\section{TREATMENT OF NEURASTHENIA}

be directly controlled by the physician is that in which the patient is required to give his full attention to what he is reading, when a series of regular vibrations can be felt by the hand. As regards the others we are obliged to depend on the patient's own report, and to leave him to rely on himself.

But, as regards concentration on one idea, there are some exercises which can be easily verified by the hand, when the vibrations give a very characteristic curve. One of these is, for instance, that of concentration on the idea of calm.

For this we will ask the patient to try to imagine his brain in a state of calm, and of moral and physical tranquillity. He should with this object evoke in his mind some idea which itself will produce that feeling. An artist will, for instance, think of a picture, of some particular landscape, another will find what he needs in a piece of music, or, perhaps, in some lofty sentiment such as prayer. Once this feeling has been attained he will try by his will to make it clearer and to prolong it. It can easily be verified; as soon as calm begins to take possession of the brain, the hand notices a change in the vibrations, which become slower and longer. 
Concentration on the idea of energy. This is obtained in a similar way, by the patient becoming conscious of his strength by recalling some occasion on which he felt really energetic.

He should try to impress on his mind the meaning of "energy" and what it can be; after a little perseverance this feeling will soon take form in his brain, and can be felt by :he hand as a series of voluntary, that is to say, more accentuated, vibrations.

Concentration on the idea of control. This urises naturally from the two preceding forms, or as soon as the patient can be calm or znergetic at will, he has the power of controlling nimself, and it will not be very difficult for him :o understand what is meant by the sensation of control. The repeated affirmation that he $s$ under control at a certain moment, if true, vill gradually develop the exact feeling of the aculty of which he stands so much in need.

The vibrations produced by concentration on he idea of control are longer and stronger than he usual vibrations, and are not a sequence of hrobs such as are the result of concentration in the idea of energy, but a series of calm, firm nd very regular undulations.

At the beginning it is sufficient if the patient ealizes this feeling of calmness, energy and 
control for a few seconds, and he will by force of habit be able to increase it if he tries to recall it several times a day in whatever circum. stances he may find himself. If his brain acquires such proficiency that he can at any moment become conscious of this feeling, he will see how useful it can be to him.

This method may, of course, be applied to other ideas and sensations according to the changes to be brought about in the patient's condition, and according to the characteristics of the illness.

PHYSIOLOGICAL EFFECTS OF CONCENTRATION.

We have just seen the effect of concentration on the brain whether from a mechanical point of view, namely, by altering the vibrations, or from the psychical point of view; in addition to. these there exists quite another class of interesting and little known phenomena which must not be lost sight of.

These are the physiological results of concentration which may thus be classified:

1. Influence on the vaso-motor nerves.

2. Influence on the organs.

3. Influence on the feeling of pain.

Effects on the vaso-motor system. I. Medical men are aware of all the changes in the vaso- 
motor system to be found in nervous persons, whether their illness affects the vaso-constrictor nerves (e.g. dryness of the skin, paleness, numbness, sensation of cold, diminution of the secretions) or the vaso-dilator nerves (e.g. profuse perspirations, redness, etc.).

All these symptoms can be modified by concentration which apparently regulates the functions in question. An instance of this may be found in the fact that many nervous people suffer from cold hands or feet, and those who have learnt the method can by a few minutes' concentration easily restore warmth to their members. The feeling of numbness, which is so troublesome on waking to certain neurasthenic persons, can also be dispelled by this method, without any movements being necessary.

We have thus seen how intense perspiration can be suppressed, and how excessive secretions, redness, etc., can be diminished and overcome, etc.

2. The following results will be observed with regard to the organs:

Heart. Increase or decrease of the beats of both heart and pulse. We have known the beats show a decrease of fifty as a result of a minute's concentration by the patient.

Lungs. Regulation of the breathing. 
Stomach. Cure of spasms.

Intestines. Increase of the peristalic movements and regulation of the bowels.

Ear. The lessening or cessation of noises in the ear; we have known in one case very distinct increase of the power of hearing.

3. Pain is perhaps the symptom which can be most easily influenced by concentration, and by this means almost all nervous pains can be overcome. It would at first sight appear as though the pain would become worse on the patient's attention being directed towards it, but this is not really the case, for, as a matter of fact, when the act of concentration is well performed, instead of an impression of pain being received, a healthy sensation is imparted by the brain to the spot affected.

This can be proved by the following simple experiment :

Pinch some part of the patient's body and ask him to concentrate his mind on the part; if the concentration is well done, the feeling of being pinched disappears at the moment when the healthy impetus to the nerves arrives at the place indicated.

In all these experiments the patient has no need to trouble himself about the results he hopes to attain, all he need do is to think 
of the organ, or part of the body he wishes to influence.

We do not think that these phenomena should be considered as coming under the head of suggestion or auto-suggestion, for they take place independently of any idea or wish of the patient, and constitute a field which is still quite unexplored, but which will certainly give many more results than those we have mentioned. 


\section{ELIMINATION AND DE-CONCEN- TRATION.}

$W_{E}$ have shown the patient how he should concentrate his thoughts or ideas, we will now teach him the reverse process, namely, how to efface an idea from his brain.

As a rule the patient is merely recommended to think of something else, a proceeding which seems so simple to a healthy man but is generally impossible for a neurasthenic person, as he only succeeds in fixing the idea more firmly in his head. He should, therefore, first learn to eliminate the idea by boldly attacking it.

The following is the most simple mode of training :

First exercise. The patient should place from three to five different objects side by side on a sheet of white paper, and then, after impressing them well on his mind, remove one from the paper while at the same time effacing all recollection of it ; when doing this it is well for him 


\section{ELIMINATION \& DE-CONCENTRATION 7 I}

to close the eyes and make sure whether the object in question has been effaced from his mind, this is most important.

He should then do likewise with a second and third object, and so on until all of them have been removed, when, if this has been well done, his mind will retain nothing but the impression of a sheet of white paper.

This experiment, though it may appear very childish, is most useful, for, if often repeated, it teaches the brain the habit of elimination.

Second exercise. Tell the patient to imagine two or three figures in his mind and then to efface them in succession; when this has been done, no impression of a figure should remain on the brain.

Third exercise. Put two objects before the patient and tell him, after effacing one of them, to retain the impression of the other; this can also be done with two words, figures or phrases.

The physician can easily feel with his hand whether the exercise is well done or not. If, for instance, you ask the patient to think of the figures 3 and 5 , when the figure 3 is thought of the vibration will be felt on the left side of the forehead and on the right side when the figure 5 is thought of; should the patient efface the 3 


\section{TREATMENT OF NEURASTHENIA}

and retain the impression of the 5 , the vibration will still be felt on the right side.

In the case of two objects the same phenomenon is produced, the object to the right of the patient being impressed on the right side of the forehead, and vice versa. It is interesting to note that neurasthenic persons do the contrary to what they wish to do, and at the beginning of the treatment their brain always retains the impression of the figure or object which they wish to efface from it; this often takes place without them being aware of it, and from this it will be seen why it is difficult for neurasthenic persons to efface an idea that worries them.

We will also make use of another means of elimination, which may be called "de-concentration," as it is the opposite of concentration on the figure $\mathrm{I}$. In this case, after concentrating on the figure in question, the patient should efface it gradually and voluntarily, which latter is a most important point, as the figure should in no case disappear contrary to the wish of the patient.

The necessary exercises are as follows:

I. He should imagine in his mind the figure in question, continuing to think of it as becoming smaller until it completely disappears. 


\section{ELIMINATION \& DE-CONCENTRATION 73}

2. He may also imagine it as retreating further and further until no longer visible.

3. Instead of imagining the figure 1 as retreating into the distance, the patient may gradually lengthen the periods of repose which should exist between those of concentration. This repose should last for one second, later for two, three, or four seconds, and, of course, during this period of repose all ideas should be effaced from the mind.

4. In this last example the mind should, after having been concentrated on the figure $\mathrm{I}$, be put into a state of repose for as long as possible ; if some thought should then come into the mind, the patient should efface it by concentrating afresh on the figure $I$.

The further advantage of the last two experiments is that the brain acquires a habit of repose, and this state, if sufficiently prolonged, is almost certain to induce sleep, and is thus the best remedy against insomnia. 


\section{THE WILL.}

WE have now reached the most important part of the training, for it is through the strength of his will that a neurasthenic person can recover the powers which he has lost.

The first thing noticed is that the will itself exists as a force in every individual, whether he be healthy, neurasthenic or even one lacking will power. It is not so much that this latter is lacking in will as in the power to use it, or in the ability to use it aright.

We will begin by defining will power, and for this purpose shall in the first place base our observations on the state of the brain as soon as the will power is brought into play.

We find that as soon as the patient decides: to will or makes up his mind to use his will, the physician feels as though something in the brain had suddenly been unlocked, and he also feels vibrations which are double or triple, according to the amount of will power 
exercised; this may be represented as follows:

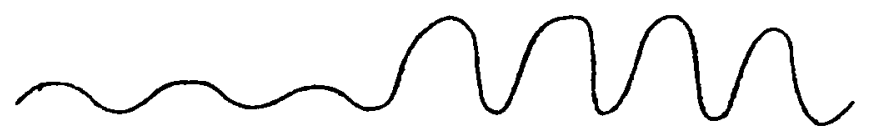

WILL

The duration of the increased vibrations varies, but these are always to be felt the moment that will power is brought into play.

Once we reàlize this invariable fact, we may define the will as a force, a special energy, possessed by every individual, and independent of every idea, showing itself under certain conditions which we will define later. This force is a component part of every human being during the whole of his life; when used naturally it increases in strength, and diminishes when unemployed; like every force, however, it is limited in power and duration, and may sometimes require rest.

We see, therefore, that this force is latent and only shows itself by an increased number of vibrations at the moment when the patient decides to use his will; when thus used we will call the action "effort of the will." 


\section{TREATMENT OF NEURASTHENIA}

\section{EFFORT OF THE WILL.}

The simplest way of describing the effort of the will, which one might with equal justice call "impetus of the will," is to compare it with the opening of the tap of a reservoir of energy, when the outflowing energy goes to stimulate some action, idea or feeling.

This force acts like the sting of a whip for a moment, and can be renewed when desired. In a healthy man its strength varies according to the requirements of the moment, for the use of the will can be controlled like everything else.

In every case of insufficient control we must take into consideration the fact, not only that the power of the will may be weakened by want of use, but especially that if it is not properly utilized there may be leakages in the reservoir, or that the uncontrolled subject may not know how to make use of his energy.

What are the results of the exercise of will power? these are, of course, the same with a healthy man as with a man suffering from insufficiency of control, and they may be looked at from two points of view.

We will first consider the mechanical point of view, which is less important, but which must 
also be understood. In this connection let us see what happens whenever the will is utilized.

I. An effort of will is never made during expiration; there is a period of cessation as if the brain were endeavouring to find a support on the breath held in the lungs.

2. There is always a more or less accentuated tension of the pulse to be noted, as also a quickening of the cerebral circulation.

3. The muscles are nearly always contracted; this is the mechanical part of the effort.

In order that the patient may obtain the best possible results, we will ask him to do the following exercise:

He should draw in a long breath, hold it for from two to four seconds, and before exhaling say to himself, "I will," while at the same time, perhaps, clenching his fists.

In this manner he will have fulfilled the mechanical conditions, namely, by finding an impetus in the breath held in his lungs, which also increases the pressure on his pulse and circulation.

"I will" may be made to apply to some act to be performed, some decision to be taken, or the patient may simply say to himself, "I will make use of my will."

Too much attention should not be attached 


\section{TREATMENT OF NEURASTHENIA}

to the above described procedure, as it is sufficient if the patient, after practising it, is able to repeat it mechanically.

We will now consider the three following -psychical conditions which are essential to the exercise of will power:

1. To know what is wished for.

2. The possibility of what is wished for.

3. The honesty and genuineness of the wish.

To know what is wished for. As there can be no exercise of will power except when it arises from some definite thought, we must first define a wish and its object. We often think we know what we wish but do not realize that the idea is far from precise. In such a case the mind cannot be fixed on an incorporate idea, consequently no result is obtained. We must, therefore, get into the habit of expressing exactly what we wish in some phrase; it will very often be seen how vague the idea was, and how little we really knew what we wished.

The possibility of what is wished for. This condition can be easily understood, for the mind is well aware of the uselessness of wishing for some impossible thing, and refuses to make an effort which it knows will prove fruitless. 
It is, however, to be noticed that even if something seems to the patient to be impossible, the physician with his hand may yet perceive that there has been some outflow of energy. In such a case one may be sure that the possibility of the action in question is perceived by the mind; a like phenomenon in the reverse sense may also take place as the mind at times declines to undertake a task which the patient considers feasible.

It must be realized that when the brain is considering the possibility or impossibility of some action, it is in a sense asking itself a question which is, as it were, answered by a second consciousness.

The honesty and genuineness of the wish. Of the three psychical conditions essential to an effort of the will, the one we are now considering is that most frequently found lacking, and we think we are right in ascribing the majority of failures to the want of genuineness of the wish.

Of these there are many causes, e.g. paralyzing doubt, fear of an effort, or sometimes even a sort of pain due to being obliged to use the will; then there are many people who deceive themselves, some unconsciously, others who know they are deceiving themselves, but 
through weakness or moral cowardice wish at the last moment to avoid the effort. Most of those who are unaware that they are deceiving themselves, are satisfied with an "attempt to will," that is to say, they would gladly use their will but cannot decide to do so; these can easily overcome this difficulty when they have been shown their mistake. It is less easy to succeed with the other class mentioned, as it is, of course, hard to be forced to recognize that one's wishes are not genuine, and that one is so ready to take refuge behind the difficulties, often really genuine, which are presented by an effort of will.

It is, therefore, very important, when making an effort of will, to be genuine and sincere with oneself, as then the desired result will be obtained.

But it must be recognized that in addition to those who deceive themselves more or less knowingly, there are a number who, especially if they have been neurasthenic since childhood, have no conception whatever of the idea of an effort of will; this can be easily understood if one realizes that this long period of suffering was spent in fruitless endeavour. These frequent failures, in which an attempt to use the will was only another word for fatigue and even 
distress, finally annihilate all sensation of will power to such an extent that the sufferers cannot even understand how others can possess this faculty. Of them it may certainly be said that they do not know how to will, but only in the sense that they do not know how to utilize their will.

As the three principal conditions essential to the use of the will have now been explained, let us see how to utilize them when educating this faculty.

The patient should begin by learning to acquire an exact conception of the act he wishes to perform, for this purpose we will take the most simple movement which necessitates the least effort; for instance, the voluntary acts of rising, walking, bending the arm, etc.

In the same way as in the case of control of the actions, the patient must, when doing this exercise, realize fully that he is impelled by his will to get up, or walk. This point is very essential, for if the will has been used, however slightly, some effort will have been made.

The amount of energy employed by the patient must then be carefully graduated; at the outset, only one movement should be required of him which should last no more than 


\section{TREATMENT OF NEURASTHENIA}

a few seconds, and be simultaneous with his effort of will.

The difficulties should be gradually increased, by asking the patient to undertake something which will last longer and be more troublesome to him ; for instance, writing a letter, or even resolving to do something and accomplishing it in a fixed time. He must remember, that, when beginning, the will power only lasts a very short time, and that he should profit by it while it lasts; he should, moreover, never go back upon what he has decided to do, as in that case he would lose confidence in himself.

The physician should take care that the voluntary actions and decisions should never exceed the energy which the patient is capable of exerting. It is unwise to attempt to overcome an unhealthy symptom before the patient is, so to speak, sure of his will power. As a rule he very soon learns to judge the effort made, to know when it is well done, and to realize the energy produced by it.

In every doubtful case or in any which can present difficulty for the patient, the physician should proceed as follows :

The patient should first say to himself :

(a) "I'll try to use my will" (with such or such an object). If he is sincere and if his 
thought is sufficiently defined, the effort will be easy, for, as a matter of fact, he will have nothing to fear but doubt, and will not need to trouble as to the result, for he is merely asked to make an attempt to use his will.

(b) "Can I do it?" (which will settle the possibility).

(c) "I have made up my mind to will" or "I'll use my will"; this naturally follows on the preceding ideas of "attempt" and "possibility," and, while affirming the patient's decision, constitutes a complete effort of the will.

For the patient the above three questions constitute a real examination of the consciousness of will power, and may be very useful to him. The physician will, at the commencement, when controlling the brain, find that $a$ (i.e. the attempt) is generally good, that $b$ (i.e. the possibility) is doubtful, and that no trace of $c$ (i.e. "I have made up my mind to will") is perceptible.

After a little training $b$ (i.e. possibility of using the will) becomes more defined, but $c$ ("I have made up my mind to will") still presents the greatest difficulty.

The effort of will must be applied, not only to the actions, but also to abstract ideas, 


\section{TREATMENT OF NEURASTHENIA}

feelings and sentiments. The patient should, therefore, be trained by this method to use his will power, by, for instance, saying to himself, "I will control myself," "I will be energetic," or "I will use my will," merely with the object of making him feel he is using his will.

In certain cases it may be useful for the patient to search his memory for what might be called "an expression of his will," and for him to recall some previous energetic action. It is really curious to see that every individual realizes his will power in a different way. The one recalls it best in an abstract idea, another by thinking of something to be done, and a third by recalling some sentiment which affects him.

An orator has been known to recall it in the delivery of a speech, and a speculator in thinking of a risky speculation; it depends on the life, temperament and habits of the patient.

\section{ERRORS.}

When describing the important points connected with the effort of will, we considered certain errors committed by the patient, such as want of genuineness, want of precision in his ideas, and the impossibility of accomplishing a certain wish. The patient's attention should also be directed to the confusion sometimes 
existing between his desires, intentions and wishes.

A desire, or even a very keen intention, does not of itself call forth sufficient energy, though it may produce an effort; it very often remains merely platonic, and, though it gives the brain a certain mechanical tension, the vibrations nevertheless do not become stronger.

From the point of view of vibrations, the desire or intention are therefore often dangerous, as they distress the patient, who is deceived by thinking that energy has been exerted but never sees the looked-for result.

It may sometimes be difficult to overcome this error, when the patient does not understand the difference between "I would like to" and "I will." He believes that he is really putting energy into his intention to use his will, and he is often very astonished that he has not done so.

We may be certain as to this if the hand is unable to feel any increase in the vibration, and if there is no sign of the "unlocking" which is produced in the brain by a good effort of will. In order to prove this to the patient, he must be told to change his wish until he finds one which will show the result required. He should then be told to realize 


\section{TREATMENT OF NEURASTHENIA}

the difference between his two efforts, when the correct one will appear simpler, calmer and truer. When the will has been utilized, there is nearly always a feeling of repose, and he is less conscious of having made an effort.

These slight differences, which are easier for the patient to feel than to explain, will give him the exact sensation of having made an effort of will.

Why is it the patient cannot decide to use his will when confronted by two alternatives?

What he does wrong is to weigh too carefully all the considerations in favour of either alternative. He loses sight of the principal reasons, and attaches most importance to the secondary considerations which pervert his judgement to such an extent that he no longer considers himself obliged to make up his mind.

The first impression is generally the best, as herein lies the chief elements of a good decision, and it is by this first impression that the patient will be guided when considering his reasons for using his will.

He should, as a rule, be taught to accustom himself to decide quickly as soon as the idea of the wish is clearly defined, for the least delay will cause him to heap one objection on the 
other until he will lose himself in secondary considerations, and even often finish by no longer knowing what he wanted.

THE RÔLE OF EFFORT OF WILL IN THE CASE OF INSUFFICIENT CONTROL.

Will power is most important in the training of control, as, if well employed, it can bring about great changes. It is, to a very great extent, through will power that the patient can gain mastery over himself, and that a person lacking consciousness can be prevented from becoming abnormal.

Psychically speaking, every passive uncontrolled idea becomes active and controlled under the influence of will power, and all the mental symptoms disappear as soon as they come under this influence, likewise the most deep-seated fears and all feelings of distress; we may, therefore, say that every patient who knows how to use his will is cured.

As soon as the patient has got into the habit of using his will, this becomes more or less automatic, and constitutes what we will call "mental recovery"; this is especially the case when he suffers from insufficiency of control.

It would be hard for a neurasthenic to feel that he had always to consider himself obliged 
to make a real effort whenever his brain should threaten to return to a passive state, but this is happily not the case, as a well-trained brain does this almost independently of its owner, as, when it simply realizes that it is about to fall back into bad ways, it can pull itself together without any conscious effort on the part of the patient. This recovery is a real effort of will which can always be felt by the hand, and also is marked by an increase of strength in the vibrations.

This mental recovery gives to some patients the sensation of a mechanical effort; one will zell you that he lifts his brain, another feels as if it were carrying out a see-saw-like movement; the curious thing is, that the patients have no idea that they are utilizing their will; they feel they are making a defensive movement, an effort to overcome a passive state.

This mental recovery is not certain when it takes this mechanical form, as in such a case the patient may some day be unable to repeat the movement which helped him; on the other hand, the true mental recovery is a guarantee that his power of control is more stable, and that it is becoming habitual. 


\section{PSYCHICAL TREATMENT.}

WITH the training of the will we finished the functional or mechanical treatment of the brain ; the patient now knows enough to cure himself; he, in fact, knows how to change an abnormal vibration; how to control his mind and how to use his will ; and he has now, while keeping an eye on his control, only to create new mental habits. He may be sure that the balance of his brain can be restored if he merely applies the lessons he has learnt.

In a great many simple cases the functional treatment may be all that is necessary; in other more complicated cases, training of a more especially psychical nature is sometimes necessary, since it is taken for granted that the mechanical training is known.

This psychical treatment deals with the idea, the conception of the thoughts and with the different changes produced on the mind by illness, as well as with the manner in 
which the latter can distort the ideas and impressions.

We would remind our readers that our purpose is merely to write for those suffering from neurasthenia, as simple and practical a treatise as possible. We will, therefore, merely cite certain facts and anomalies which are worth knowing, for they occur in every case of neurasthenia.

The above-mentioned changes are easily recognized by the physician during the functional treatment, and by the patient when he analyzes the different causes which produce a symptom, as when, for instance, a pain is produced by fear of the same. As a rule the patient perceives that the thought precedes and also causes the symptom, but as he very often is quite ignorant of its psychical cause, the physician should take pains to ascertain the psychical origin of the symptoms, for when the patient once understands them he can at any rate be on his guard against them and check them before they appear.

As already mentioned, the different psychical causes are fairly easy to ascertain, but they must sometimes be looked for in the recollections and earlier life of the sufferer.

In order to understand their importance, we will now examine some of these causes. 
REAPPEARANCE OF FORMER BAD SYMPTOMS OWING TO IMPRESSIONS LEFT ON THE BRAIN (French, "Clichés").

In all cases of neurasthenia there are some symptoms which appear suddenly under certain conditions for which there appears to be no cause. These may take the form of a fear, a feeling of discomfort or distress, or of a physical symptom such as pain, giddiness, sickness or palpitations.

These inexplicable causes are really nothing more than former impressions which have been, so to speak, crystallized in the brain, and which, unknown to the patient, always reproduce the same symptom mechanically; he is not always aware of their existence, or if he is, does not attribute to them the symptoms they produce. We will make use of the term cliche when speaking of these impressions and will now give a few examples. ${ }^{1}$

I. For some ten years Mrs. N. suffered from an affection of the stomach which took the form of vomiting at meal times; there was nothing organically wrong, and she herself could see no

${ }^{1}$ In the course of this translation it has often been found possible to give "bad impression" as a rendering of the (French) term cliche. 
cause for this. On carefully recalling the events of her earlier life she found that ten years previously she had had a violent emotion during a meal; after this she always suffered from a feeling of sickness at meal time, but when she once realized the cause the symptom was cured.

2. Besides showing all the usual symptoms of neurasthenia, Mr. B. was subject to violent fits of perspiration after a walk of twenty minutes, he was also seized with trembling of the legs, and was obliged to sit down for some time before being able to continue his walk. On careful study of the matter it was found that this phenomenon was of seven years' standing, and that it very likely was due to an attack of influenza which had necessitated his keeping his bed for three weeks. His first walk had quite naturally produced this symptom which had afterwards continued without any reason; this, however, disappeared as soon as he was aware of the cause of the former bad im. pression.

3. After the slightest effort Mr. L. used to suffer from palpitations, and had done so for several years, until it was discovered that this was due to a medical consultation when the physician had advised him to pay attention to 
his heart; the palpitations disappeared as soon as Mr. L. realized their cause.

Such examples could be multiplied ad infinitum, as a certain number of these bad impressions occur in every case of neurasthenia in a more or less pronounced degree.

Such an impression may not only produce phenomena such as vomiting, diarrhoea, etc., but also psychical symptoms, especially those of fear, moral discomfort or distress. The reappearance of the impression is generally due to an unconscious recollection of the primitive fact, without one being able to find any connection between this fact and the symptom which shows itself in the patient; at any rate it is impossible to realize how it reaches the brain. It can, however, sometimes be traced, as is shown in the following case.

One of our patients found it impossible to hear or see the number 3 without a feeling of great distress. Quite by chance we discovered that this was due to the fact that on the third day of the month several years previously a very dear relation of his had met with an accident; the patient had remembered the number while quite forgetting the cause.

The cliche generally disappears as soon as the patient realizes that it is only due to a past 
94 TREATMENT OF NEURASTHENIA

impression for which no further reason exists. It may, however, be so deeply impressed on the brain that it cannot so easily be got rid of.

The patient must then of his own accord recall the cliche until his brain feels that it is under his control, for it will show no psychical nor physical symptom if produced consciously by the patient of his own free will.

The investigation of these bad impressions is therefore of some importance, as by studying them the patient becomes conscious of phenomena which had hitherto escaped his reason, judgement, and will.

\section{THE ABNORMAL WORKING AND IDEAS OF THE BRAIN.}

In this chapter we will endeavour to ascertain what, from the psychical point of view, corresponds to an abnormal vibration, that is to say, what peculiarities characterize an idea, sensation or feeling of a patient when in a passive or uncontrolled state.

These we will call abnormal ideas, feelings or sensations, in the same way as we will describe as abnormal working any uncontrolled or insufficiently conscious working of the brain.

Every idea of a neurasthenic when in a passive state is abnormal and is always to a 
certain extent perverted, as is also every sensation and feeling.

Here the same causes must be looked for as in the case of abnormal vibrations.

r. Want of consciousness. As the idea is in reality nearly always vague and indefinite, the mental appreciation will for this reason easily be at fault.

2. Insufficient concentration. On account of this insufficiency the thought will have little stability, and hence it will be hard for the patient to think out his idea fully, as it will always be interrupted by other thoughts; he will, therefore, often reach a conclusion diametrically opposed to what he wished, and will be confused by a multiplicity of ideas.

3. The will has no power over the idea, which will, therefore, have a tendency to be exaggerated, to fix itself in the brain, and to become an obsession.

4. The idea is neither under the control of reason nor judgement, but, even though it may become absurd and quite unreasonable, is accepted by the patient.

5. As the passive state is a trying one, it does not conduce to an altruistic feeling, for the patient is only conscious of his own feelings. This state tends to produce inertia (as, owing 


\section{TREATMENT OF NEURASTHENIA}

to the patient's thoughts being centred only in the past and future, no immediate effort is required).

A feeling of want of control causes one of inferiority, which will estrange the patient from his fellow-creatures and, consequently, from his surroundings; of these he will only be dimly conscious. He is so out of touch with his life that everything will seem unreal to him. It is easy to see that a great many changes are produced by the passive state; these we have previously described.

The sensations become abnormal for the same reasons as the ideas. Their peculiarities consist in their excessive changeability, and, in that they are as little defined as the ideas, that they are prone to exaggeration and to persist without reason.

The feelings are ill-balanced, they are sometimes exaggerated, though this form is of short duration; they are more often dulled and seem to no longer exist owing to the patient becoming so wrapped up in himself. For instance, a devoted mother will lose all affection for her children, or a lover may wake up some fine morning and feel that he is no longer in love! A neurasthenic person may even lose all feeling of religion, however devout he may have been. 
It should, however, be said that once the patient is cured these peculiarities no longer exist.

In the case of abnormal working of the brain the patient never fully follows out his thought, as every idea is always being constantly replaced by others, after which the original idea will be completely forgotten or will only be recalled with difficulty.

A healthy man is easily able to follow out the sequence of his ideas, but in one not under control a part of these ideas is often unconscious, and he may arrive at quite a different conclusion to what he originally intended. I do not think I am exaggerating in saying that a neurasthenic person might say to himself with full assurance, "I am perfectly well, therefore I am ill." We need only intercalate the following unconscious deductions, "I am perfectly well, but I might get ill," "Supposing I get ill ?" "I am afraid I shall," "I think I am going to be ill," "I am ill."

In' this chain of thought the patient only s remembered that his brain had followed out a sequence of plausible or exact arguments and that it had reached a correct conclusion. The fact that these symptoms are met with must be taken for granted, as it would not be possible to explain how they are produced. 


\section{TREATMENT OF NEURASTHENIA}

The cause of these anomalies must then be looked for in the psychical treatment, and we must open the patient's eyes and make him understand the reason for these mental defects, and how little importance he should attach to every passive idea and sensation; when once this is realized he can correct his faults, which previously had only existed owing to his ignorance.

Though not abnormal, a whole series of thoughts and feelings are, in themselves, uncontrolled passive ideas, as, for instance, fright, fear, doubt, envy, hatred, jealousy, etc.; others may be both active and passive, as, for example, remorse. When a man is seized with active remorse, while recognizing his fault, he tries to overcome it and to amend his ways, whereas passive remorse would, on the contrary, crush him, and he would bewail his fault without making any effort to master himself. Passive sadness is a mixture of careless negligence and selfishness, whereas active sadness is healthy and good.

The importance of distinguishing between these two states is very great, whether it be from the moral or psychical point of view, and many sad results might be avoided if the abovementioned facts were throughly understood. 
It is, however, easy to be on one's guard, for every passive thought does harm and causes moral and even physical discomfort, which in the latter case acts as' a real toxine on the human organism.

We might speak of the false conceptions of life and of the revolt of the individual against facts that he will not accept, as these make him passive owing to his being the slave to one thought and feeling, but this would go beyond our limits, for we cannot here go into the question of morals.

The patient should also be warned against exterior impressions; here it is not a question of abnormal ideas or working of the brain, but of a diminution or even abolition of its reactive faculties.

DIMINUTION OF THE REACTIVE FACULTIES.

The brain of a normal man is so constituted as to be able to overcome all outside influences which might interfere with its proper working. A neurasthenic person, on the other hand, is very highly sensitive, and, relatively speaking, is more influenced by slight impressions than by weightier ones. It has, in fact, been found that a patient may be greatly upset by something of no importance, but be little affected by 


\section{TREATMENT OF NEURASTHENIA}

a severe mental shock, which, owing to its severity, will have aroused his reactive faculties and left him defenceless against the minor event.

All incidents of daily life, all changes of temperature and atmospheric pressure, whether of heat or cold, dampness or dryness-for one or other is peculiar to every patient-everything affects him morally or physically, a little annoyance is hugely exaggerated, and when slightly deceived he feels a disaster has befallen him, etc.

All these phenomena appear absurd to a man whose brain is controlled and in a normal state, as in his case the brain rejects everything that might harm him; it may be said to resemble an india rubber ball which, owing to its elasticity, can regain its original shape when this has been momentarily altered by a blow. Quite the opposite effect will be perceived in a man with insufficient control, as in his case a slight shock may produce a very deep impression, which may be difficult to efface.

We will now show the patient how this sensitiveness can be lessened and how healthy physiological reaction can be re-established.

The following axiom must first be impressed on him: "No outside influence can affect the 
brain in an absolute manner," that is to say, that, though it naturally feels the impressions, whether strong or weak, it should nevertheless a priori be always considered capable of acting and of overcoming them.

The patient must start with this principle in order to be able to defend himself, for by this means he will arouse the normal reactive faculties of his brain and increase his powers of resistance; he will also gain in self-confidence, and no longer be a slave to every outside influence; no matter how confident he may feel of his control, as long as he does not admit this assertion he will be sure to suffer from relapses, and will, in fact, never overcome them, for, as his feelings and symptoms arise from an exterior cause, it would seem to him logically impossible to fight against them.

$\mathrm{He}$ would be right in thinking thus if these symptoms arose from any outside cause, but here is where he is mistaken, for this only occurs if the brain is in a passive state, and therefore without reaction.

We would strongly advise the patient to try, by making many experiments, to verify the above assertions; if he does this he will be throughly convinced. Outside causes cannot provoke unhealthy sensations, except on a brain 
in a passive state; a brain in an active state is always capable of reaction. When duly warned and enabled by previous treatment to change the working of his brain, the patient will have nothing more to fear.

The beginning of such relapses is often very insidious, and the patient may find it difficult to distinguish between what is nervous and what normal. This is exemplified by the following case :

Mr. M. C. went home believing himself quite cured, but on his journey got an ordinary cold, when his doctor, who knew him to be very impressionable, advised him to take care and stay in his room. He gradually became depressed, and always had a feeling of pain and heaviness in his head, then the tired and exhausted feeling got worse, all work became difficult, and all the phenomena of his former illness returned. As he attributed everything to his cold, he did not attempt to fight against this feeling, and it was not until a month later that he wrote in his perplexity and asked for advice. All was cured as soon as he had realized his. mistake.

We could speak of a number of similar relapses, due to even more trifling causes, such as fits of anger, small daily events, etc.; among 
others we know of a case where the patient became ill owing to the number on his spectacles having been changed. The same mistake occurs in all such cases, viz. the patient, thinking it useless, does not fight against the symptoms.

CAUSE OF RELAPSES.

We will now endeavour to find out the principal causes of relapses among patients who are under control, ignoring those found in cases which have not been completely cured, as such are not real relapses. In these cases there may be a momentary cessation of symptoms, but as this often occurs in the form of intermittent neurasthenia, when, in spite of the appearance of health, the brain remains in an abnormally excited state, it cannot be considered as an absolute proof of a cure.

In our opinion, the patient will not be cured until he masters his brain, in which case he will feel sufficiently sure of himself not to fall ill again, though the danger is that he may be no longer on his guard, and that his brain easily returns to the bad abnormal habits, and thus, through careless negligence, he falls into the dreamy state, though without disagreeable symptoms. The patient knows what is happen- 


\section{TREATMENT OF NEURASTHENIA}

ing, but does not trouble himself, as he thinks he can so easily return once more to an active state. Then the condition he is in becomes habitual until he finds himself in a critical state, which he has great difficulty in overcoming.

After he has received treatment, it is necessary for him, even though he is under control, to continue the examination of his brain with care and attention for several months; this we would earnestly recommend our patients to do.

This self-examination must, however, not be exaggerated, for if overdone it might be another cause of relapse.

We have known patients who were perfectly cured, but who worried themselves for months by constantly examining the state of their brain, and that for no reason, as no symptom showed itself, and there was nothing wrong, except that the patient had too little confidence in himself.

This constant agitation tires the most normal brain, and, if the patient is not reassured by some convincing experience, he finally produces his former illness by auto-suggestion. $\mathrm{He}$ becomes persuaded that he is suffering from fits of great distress, that there is again cause for his fears, and that he is about to be attacked by all the phenomena which accompany nervous illnesses. On his brain being examined, it is 
found to be perfectly calm, and though sometimes agitated no abnormal vibrations are perceptible. This form is easily diagnosed; in such cases the patient's brain is in an active state, though he is unaware of this, and hardly wishes that it should be so.

These causes more often depend on the patient, as they are former bad impressions (cliches) which have not been completely effaced, or which the patient did not wish to mention, which later take the form of the diminution of what we have called the reactive faculties of the brain.

External causes are more uncommon; mental or physical shocks, even when severe, have certainly a depressing effect, but as a rule this does not last, or cause a complete relapse in a patient who is under control.

We will consider certain operations and traumatisms as exceptions, especially when there is a shock to the brain, as here it is rather a case of the development of another illness than of a relapse.

We have now fully described our system of the education of brain control, having shown the patient what we think may be useful to him, and what may give the physician an insight into our method. 


\section{I06 TREATMENT OF NEURASTHENIA}

The psychical portion has been kept within as narrow limits as possible, as it does not differ from the well-known methods of psychotherapy, and any fuller mention on our part would appear useless, as it has been so frequently dealt with by more competent writers than ourselves.

We will now only say a few words on insomnia and our mode of treatment. 


\section{INSOMNIA.}

INSOMNIA is one of the most obstinate and depressing symptoms of neurasthenia. A bad day generally follows a bad night, as the patient no longer has sufficient courage to fight against his feelings, and thinks that in not doing so he is fully justified by his fatigue. $\mathrm{He}$ attaches such great importance to his sleep, and especially to the length of time he has slept, that this is for him often a very important symptom. How many people there are who say that if only they could sleep they would be cured!

This belief is more illusory than real, though we are quite ready to admit that any one suffering from insomnia is more likely to give way to difficulties and to become passive. But how many patients there are who sleep for ten or twelve hours, and yet are as ill on waking as when they went to sleep.

What we can assure the patient is, that however troublesome this symptom may be, he is 


\section{TREATMENT OF NEURASTHENIA}

not cured when once he is able to sleep, and, further, that the quality of his sleep is far more essential than the amount.

Sleep naturally returns as soon as there is a certain amount of improvement in the patient's condition, but, as this is sometimes slow to appear, we must try to help him to regain his sleep, which he finds is so hard to do without. For this purpose we will try to find out the causes of insomnia, to describe its different forms, and, after doing so, to lay down the necessary mode of treatment.

Causes of insomnia. The chief and primary cause is always insufficiency of control, which shows itself in different ways. The patient may, for instance, be unable to stop the current of his thoughts or he may suffer from some fear, such as fear of noise, owing to his hypersensibility of hearing, or to fear of not sleeping, which is perhaps the most usual form.

The fact of waking up or of broken sleep may also, to a very great extent, be attributed to former bad impressions (clichés). Palpitations have, for instance, been known to return at a fixed time during the night, and sometimes insomnia is simply caused by the fact of the patient constantly recalling to his mind the 
memory of having awakened on some former occasion.

All these causes are, therefore, amenable to training. We will distinguish between :

I. Partial insomnia.

2. Complete insomnia.

1. Partial insomia. This may take the form of a sort of slight coma, which does not give the patient a feeling of sleep.

In such a case we would advise him to throughly rouse himself, even if he should have to do so several times during the night, and then to try and regain a better sleep by the help of the following exercises. Another form of partial insomnia is when the patient sleeps profoundly for one hour or more, and then, for no reason, awakes for a certain space of time, which may or may not last for a definite period. This form is nearly always due to some bad impression of which the cause must be first ascertained, when, before going to sleep, the patient should make up his mind that he will awake at a different time; as soon as he can manage to change the hour of waking, he will have almost conquered this form of insomnia.

Broken sleep is generally caused by hypersensibility of hearing and the fear of noise, the patient going to sleep when the noise has 


\section{IIO TREATMENT OF NEURASTHENIA}

stopped, while in certain cases the anxiety lest he should be again awakened is enough to prevent him gaining any sleep.

The simplest treatment is to accustom the patient to noise; he may also on waking, voluntarily concentrate his mind on the cause of his waling, when his fear will be dispelled by this concentration.

2. Complete insomnia. This is very often caused by the fear of not sleeping, which fear is so strong that the best narcotics prove of no avail.

The method which we have found the most effective, though it may appear strange, is that of asking the patient to refrain from wishing to go to sleep in a fixed time; he will immediately notice that if he has really done this in all sincerity his anxiety will disappear and he will feel able to sleep.

It is essential that he should hold to his determination for the fixed time, and that he should even fight against sleep. Should his former fear return on again endeavouring to sleep, he must repeat his resolution. He may be sure that he will soon get the better of his brain and regain his sleep.

We have known patients who have not gone to bed for one or two nights in succession which, 
though certainly an heroic effort, was always crowned with success, if they were sincere in their determination.

Another form of complete insomnia is that of a patient not sleeping because he is not sleepy. This feeling is, so to speak, due to lack of will power (abolie), for the patient suffers from no fear or bad habit, his brain is calm though throughly awake, and it is in this manner that he rests himself. This form is uncommon, and as exercises have little effect we would recommend hypnotism.

We will not deal with forms of insomnia which may be due to pain or certain organic causes, for here it is not a question of insufficiency of control.

All exercises for regaining sleep are beneficial if they restore calm and cerebral controi, but the following are more especially recommended :

What we have called deconcentration is almost certain to produce sleep, if the patient has succeeded in bringing about a restful feeling for a certain length of time. He should concentrate on the figure $\mathrm{r}$, and then try to efface it from his mind by thinking of it as slowly receding. All distracting or intervening ideas should be checked by reconcentrating the mind on the figure $\mathbf{I}$. 


\section{TREATMENT OF NEURASTHENIA}

Concentration on the idea of calm or rest is also highly beneficial.

A very simple method is to think of the breathing, which should be regular, and then slightly sonorous, like some one who is going to sleep.

A good result may often be obtained when the curves of the figure $\infty$ are thought of in regular succession.

A strong wish to sleep on the part of the patient may be very efficacious if all doubts can be effaced.

All these exercises, if they are to succeed, can only be carried out after a certain amount of training, for if the patient is devoid of concentration no good result can be obtained.

As the use of narcotics should be avoided as far as possible, we use them very seldom, and only on commencing the treatment. They always have the great disadvantage of making the patient more or less passive on the following day, not to mention the fact that he is likely to become dependent on them, and that in the long run they always have a deleterious effect. 


\section{SUMMARY OF TREATMENT.}

WE will now conclude by giving as concise a sketch as possible of our method of treatment.

However long and troublesome the account of the patient's illness may be, it should nevertheless be listened to with attention, for the physician may be enabled thereby to decide on certain points in the treatment, to discover some traces of former bad impressions (clichess), and to place his patient in one of the two following classes :

I. Where there is predominance of psychical symptoms.

2. Where there is predominance of organic symptoms.

In the first category the symptoms may be ascribed solely to the brain, and the training of control may be at once commenced.

The second class comprise those who attribute their illness to some organ, such as heart, stomach or intestines. 


\section{TREATMENT OF NEURASTHENIA}

Before commencing treatment it is important to make a careful examination of the organ in question, should there be the slightest lesion, or even the smallest sign which might appear to indicate the necessity of medical or dietetical treatment, it is highly recommended that the result of these should be first awaited. As we require the patient to rely only on himself, and not on any drug, it would hardly be reasonable to ask him to follow out two treatments which might be in opposition to each other.

At the outset he wants especially to know and understand what is the matter with him; it will give him confidence if he is shown why he is ill, what are the causes of his symptoms, and how to get well. He will not then be discouraged as he had so often been before, by being told that he was suffering from nerves. How many sufferers have been comforted by being made to understand what they could not themselves explain. It is not difficult to make the patient realize his defects and his insufficiency of control ; this is highly important, for as long as he remains ignorant of the causes and origin of his illness, it is impossible to carry out the training of his brain.

We must then begin by showing him how to recognize his various conditions, passive and 
otherwise, after which he should turn his attention to his conscious and voluntary movements, which should be carried out as frequently as possible during the day, as they form an excellent training and discipline.

At the same time, he should be given the first exercises of concentration, viz. :

I. Concentration on the different parts of the body.

2. On the symbol of infinity $\infty$.

3. On the figure I.

These exercises should, on an average, be carried out for ten minutes every two hours; as soon as they can be sufficiently well done the physician should commence the training of the will as already described.

When the patient is able to change the working of his brain by means of his will, his concentration, or by performing conscious acts, he must begin to put into practice what he has learnt, and try by means of his exercises to modify his passive state and to overcome all his symptoms.

$\mathrm{He}$ should note and criticize every good or bad result, as he will gain confidence by his experiences; this is essential, as his treatment is founded, not on what is told him by the physician, but on what he himself does. 


\section{II6 TREATMENT OF NEURASTHENIA}

Any very sudden improvement at the outset is almost always due to auto-suggestion, and is of no lasting duration.

In spite of the best intentions on the part of the patient, his progress will not necessarily be steady, so he should be warned that relapses are practically certain to occur.

These are, however, of use to him, as, through them, he learns how to defend himself, and by this means acquires his best experiences.

After learning the first concentration exercises he should be taught the different methods of elimination and of deconcentration, and then of concentration on an idea pure and simple.

Finally, he should learn how to recognize and overcome abnormal ideas, faulty working of his brain, or any symptoms due to former bad impressions (cliches). This is the general idea of the treatment which must, however, be adapted to the needs of each patient.

Duration of the treatment. This necessarily varies, but two or three months should be suffcient in which to teach the patient how to carry out the treatment by himself. Three to six weeks suffice for the simpler cases, but in the more serious ones it is advisable that after the patient has been dependent on himself for a 


\section{SUMMARY OF TREATMENT}

few months he should again see the physician. This supervision is principally in order that he may be able to correct any faults into which the patient may have fallen when left to himself, and will, as a rule, only take a short time.

Results of the treatment. We have, by experience, become more and more convinced that insufficiency of control can and should be cured even in inveterate cases, and when the sufferers have been ill for twenty years or more.

It would be difficult to give the exact statistics of the cases which have been completely cured, for this would necessitate our seeing the patients after a year or two, and this seldom occurs.

In any case, however, the results obtained have certainly surpassed our hopes, and have well rewarded our labours. 


inte
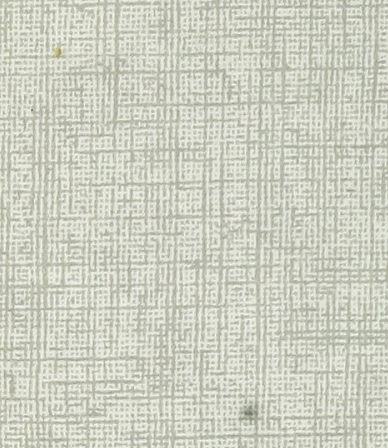

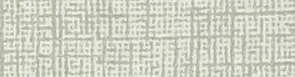

15.4.

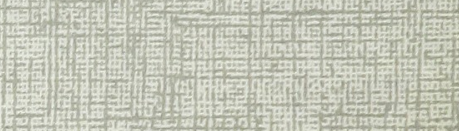

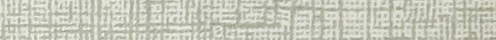

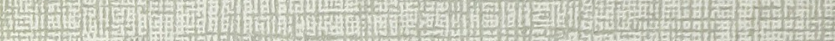

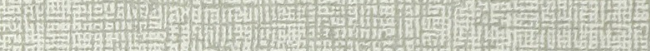

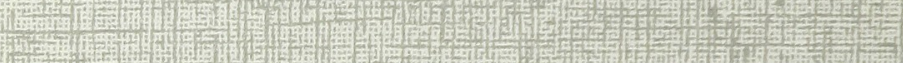

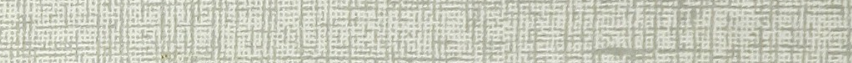

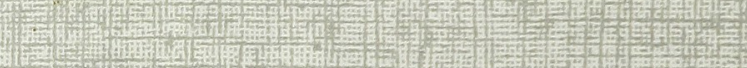

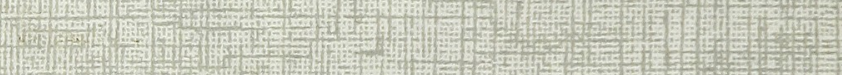
(3) (1) (1)

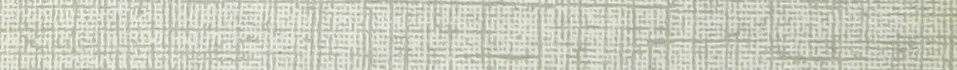

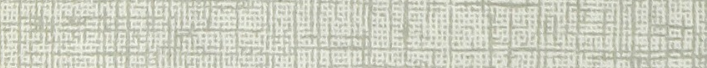

